\title{
Evaluating Smoldering Behavior of Fire-Blocking Barrier Fabrics
}

Shonali Nazaré

William Pitts

Szabolcs Matko

Rick D. Davis

This publication is available free of charge from:

http://dx.doi.org/10.6028/NIST.TN.1859

January 2015

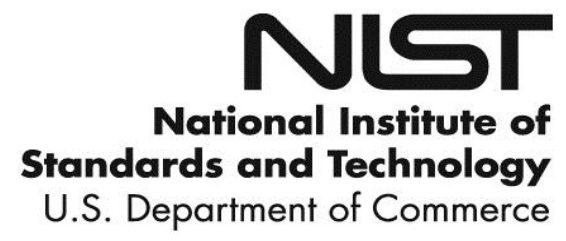




\section{NIST Technical Note 1859}

\section{Evaluating Smoldering Behavior of Fire-Blocking Barrier Fabrics}

Shonali Nazaré

William Pitts

Szabolcs Matko

Rick D. Davis

Fire Research Division

Engineering Laboratory

This publication is available free of charge from:

http://dx.doi.org/10.6028/NIST.TN.1859

January 2015

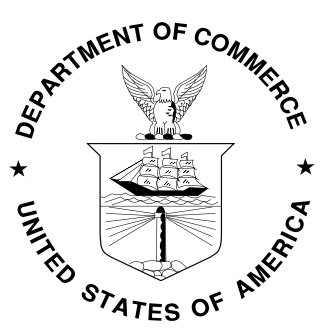

U.S. Department of Commerce Penny Pritzker, Secretary

National Institute of Standards and Technology Willie May, Acting Under Secretary of Commerce for Standards and Technology and Director 
Certain commercial entities, equipment, or materials may be identified in this document in order to describe an experimental procedure or concept adequately. Such identification is not intended to imply recommendation or endorsement by the National Institute of Standards and Technology, nor is it intended to imply that the entities, materials, or equipment are necessarily the best available for the purpose.

National Institute of Standards and Technology Technical Note Natl. Inst. Stand. Technol. Tech. Note 1859, 35 pages (January 2015) CODEN: NTNOEF

This publication is available free of charge from: http://dx.doi.org/10.6028/NIST.TN.1859 


\begin{abstract}
This study reports on the smoldering propensity of commercially available barrier fabrics (BFs) in a small-scale mock-up configuration. Most BFs are smolder resistant when tested alone over a standard flexible polyurethane foam (FPUF). However, when covered with a smolder-prone cover fabric (CF), most BFs failed the smoldering ignition test described in the Consumer Product Safety Commission's proposed standard 16 CFR 1634. Results of this study suggest that the smolder-prone CFs, when placed on top of a number of BFs, are capable of releasing sufficient heat to initiate the char-oxidation smoldering process of some of the BFs and subsequently transmit the heat to the underlying FPUF. A smoldering index for BFs was derived from the measured char volume fraction (CVF) of the FPUF by varying the BF component in the FPUF/BF/CF mock-up systems, while holding the other two components constant.

Of the 20 BFs tested in this study, five BFs self-extinguished and passed the smoldering ignition test criterion as described in the proposed 16 CFR 1634. The smoldering index for these BFs was zero. BFs with smoldering index of 1 or more resulted in sustained smoldering in the FPUF. The smoldering propensity of BFs and the amount of heat transmitted to the FPUF varied depending on the BF structure, fiber content, air permeability, and bulk density. Flame retardant treatments and use of char forming fibers showed a greater tendency for BF smolder in the presence of the smolder-prone $\mathrm{CF}$. BFs with char-forming fiber blends had greater smoldering propensity as compared to BFs with low charring fiber blends. The lower the smoldering propensity of the BF, the less likely was the development of sustained smoldering in the FPUF.
\end{abstract}

Keywords: upholstered furniture; barrier fabrics; smoldering; air-permeability; char length; mass loss 
This page left intentionally blank 


\section{Contents}

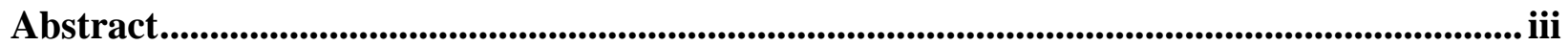

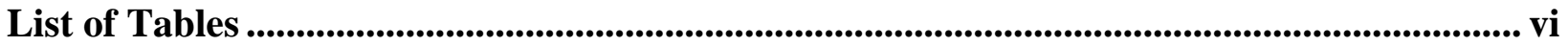

List of Figures........................................................................................................................................ vii

List of Acronyms and Abbreviations ........................................................................................... viii

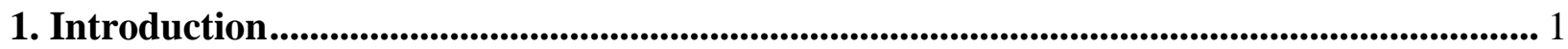

1.2. Existing test methods for assessing smoldering ignitability of BFs ............................... 2

2. Experimental Materials and Test Methods ..................................................................................... 4

3. Results and Discussion........................................................................................................................ 7

3.1 Cigarette-induced FPUF smolder ………………................................................... 7

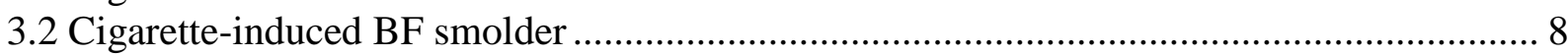

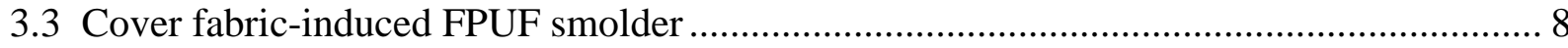

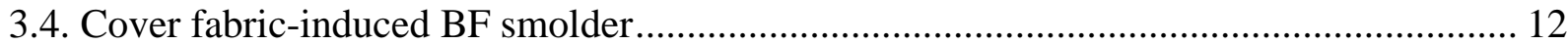

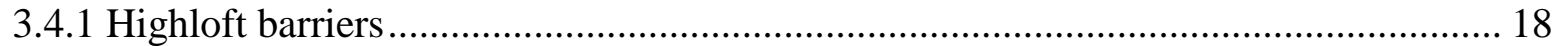

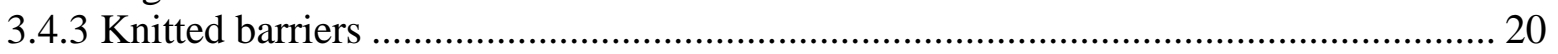

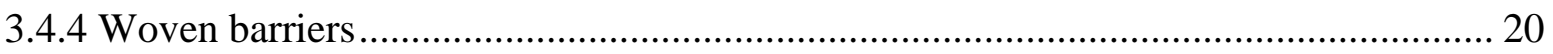

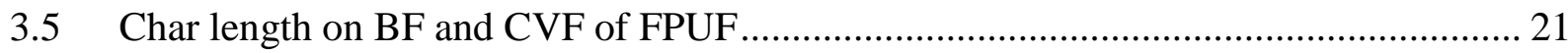

3.6 Air permeability of BF and CVF of FPUF.............................................................. 22

4 Conclusions and Future Work............................................................................................. 23

References.............................................................................................................................................. 25 


\section{List of Tables}

Table 1. Standards and test methods for assessing smoldering ignitability of BFs.................... 3

Table 2. Description of BFs used in soft furnishings. Uncertainties are reported as Type A uncertainties with experimental standard deviations. Values are reported with $2 \sigma$ uncertainty ... 5 Table 3. Digital images and char lengths of charred BFs tested in a mock-up configuration with and without smolder-prone $\mathrm{CF}$

Table 4. Digital images of FPUF/CF mock-up assemblies and char damage on FPUF at the end of $15 \mathrm{~min}, 30 \mathrm{~min}$, and $45 \mathrm{~min}$ test durations

Table 5. Mass loss, CVF and derived indices from smoldering ignition resistance test for FPUF/BF/CF composites. Uncertainties are Type A uncertainties ${ }^{49,50}$ based on experimental standard deviations. Values are reported as $2 \sigma$ (i.e, coverage factor of $95 \%$ )........................ 15 


\section{List of Figures}

Figure 1. Real-time mass loss (A) and mass loss rate (B) curves for a FPUF/CF mock-up assembly.....

Figure 2. Real-time percent mass loss of complete mock-up assemblies during smoldering ignition resistance tests for: (a) highloft, (b) nonwoven, (c) woven, and (d) knitted barrier materials.

Figure 3. Char volume fraction (CVF) of FPUF during smoldering ignition resistance test for BFs in the presence of a smolder-prone cover fabric. ............................................................ 16

Figure 4. Relative changes in char volume fraction (CVF) of FPUF with and without BFs....... 17

Figure 5. CVF of FPUF versus char length on BF ...................................................... 22

Figure 6. CVF of FPUF at the end of 45 min smoldering ignition tests versus air permeability. 23 


\section{List of Acronyms and Abbreviations}

$\begin{array}{ll}\text { ASTM } & \text { ASTM International } \\ \text { BEARHFTI } & \begin{array}{l}\text { California Bureau of Electronic and Appliance Repair, Home Furnishings } \\ \text { and Thermal Insulation }\end{array} \\ \text { BF } & \text { Barrier fabric } \\ \text { BHFTI } & \text { California Bureau of Home Furnishings and Thermal Insulation } \\ \text { CAL TB } & \text { California Test Bulletin } \\ \text { CFM } & \text { Cubic Feet per square Meter of sample } \\ \text { CFR } & \text { Code of Federal Regulations } \\ \text { CPSC } & \text { Consumer Product Safety Commission } \\ \text { CVF } & \text { Charred Volume Fraction } \\ \text { FPUF } & \text { Flexible Polyurethane foam } \\ \text { FR } & \text { Flame Resistant } \\ \text { HTP } & \text { Heat Transfer Properties } \\ \text { NFPA } & \text { National Fire Protection Association } \\ \text { NIST } & \text { National Institute of Standards and Technology } \\ \text { SPUF } & \text { Standard Polyurethane Foam } \\ \text { SRM } & \text { Standard Reference Material } \\ \text { RUF } & \text { Residential upholstered furniture } \\ \text { UFAC } & \text { Upholstered Furniture Action Council } \\ \text { w/o } & \text { Without }\end{array}$




\section{Introduction}

Fire-blocking barrier fabrics (BFs) are predominantly used in soft furnishing products that are required to comply with open-flame flammability regulations, for e.g., the $16 \mathrm{CFR} 1633,{ }^{1} \mathrm{Cal} \mathrm{TB} 129,{ }^{2} \mathrm{Cal} \mathrm{TB} 603,{ }^{3}$ Cal TB 133, ${ }^{4}$ FAR $25.853,{ }^{5}$ etc. These materials interposed between a cover fabric $(\mathrm{CF})$ and the soft cushioning modify the thermal response of the upholstery by limiting heat transfer and gas flow in the upholstered assembly. This essentially limits the product involvement in a fire by preventing and/or significantly delaying the ignition of interior cushioning materials, lowering the heat release rate, reducing the rate of flame spread and/or extinguishing the flames from an exterior CF or ticking. ${ }^{6}$ Flexible polyurethane foam (FPUF) is one of the most flammable materials that contribute to the high heat release rates observed when upholstered products catch fire. Generally, the flammability of FPUF has been addressed by adding flame retardants. However, concerns have recently been raised about potentially harmful human health and ecological effects of fire retardants, and the effectiveness of fire retardants at the levels typically used in residential upholstered furniture (RUF) meeting the California TB 117 standard has been questioned. ${ }^{7,8}$ As a result of such concerns, California TB 117 has been updated to remove an openflame test requirement for RUF soft cushioning materials, which was the primary driver for adding fire retardants to RUF in the United States. ${ }^{9}$ A promising approach for reducing the flammability of residential upholstered products, without compromising aesthetics and comfort, is to incorporate a BF. BFs, also known as interliners, have been previously used to comply with Cal TB 133 requirements ${ }^{4}$ for upholstered seating used in public places and vehicles of mass transport. ${ }^{5,10}$ Most standards issuing authorities in the United States, including the Upholstery Furniture Action Council (UFAC), ASTM, and the National Fire Protection Association (NFPA), require that BFs pass a smoldering ignition test when a smolder-prone cover fabric, referred to as a Class II fabric by UFAC, is used in RUF.

Generally, a polyester batting is used under the cover fabric to provide a barrier to smoldering ignition sources and to achieve durability, aesthetic, and comfort effects. ${ }^{11}$ Polyester battings are less susceptible to smoldering as most of the heat from the smoldering cigarette and cover fabric is consumed in melting the polyester fibers. Polyester melts and shrinks away from the heat source ${ }^{12}$ and moreover, the low density structure of polyester batting increases its effectiveness as a thermal insulator. ${ }^{13}$

Following the introduction of an open-flame regulation for mattresses (16 CFR 1633 $)$ in 2007, several new fire-barrier technologies, discussed elsewhere, ${ }^{6}$ have been commercialized. One of the objectives of this study is to assess the potential of incorporating similar BFs to those used by the residential mattress industry to improve the fire performance of RUF.

In order to improve upholstered product fire safety, BFs must protect the cushioning layer from both flaming ignition and smoldering ignition sources. In a previous study, we evaluated the potential fire-blocking performance of barrier fabrics when exposed to open-flame ignition sources. ${ }^{14}$ Intrinsic properties that influence the heat transfer properties (HTP) of BFs, as related to thermal protection of cushioning components in upholstered products, were identified. When tested for heat transfer characteristics, the area density and thickness of BFs had a strong influence. However, when tested as a composite in a mock-up assembly, the performance of active and passive barrier materials showed clear differences. For chemically-active BFs, the construction parameters and material properties such as thickness, air permeability, and heat transfer were of little significance. In the case of passive BFs, however, these parameters became decisive. Results from this study ${ }^{14}$ suggested that if a BF is not an active fire barrier, 
then the amount of heat transferred through the BF is critical, i.e., the material should be thermally thick to protect the underlying cushioning layers.

BFs used in mattresses generally pass the smoldering ignition test largely because of the use of thermoplastic tickings (i.e., covering fabric), and/or polyester batting under the ticking. Moreover, mattresses pass the smoldering ignition test due to the fact that, in a flat configuration, most of the thermal energy from the smoldering cigarette used as an ignition source is lost to the environment at ambient conditions. However, smoldering conditions in a crevice formed between two or more cushions, such as commonly found in RUF, can be very different from the horizontal configuration of a mattress. In a crevice configuration, the maximum amount of thermal energy from a smoldering ignition source is directed into the cushioning layers which, depending on the structure and composition of the cushioning material, can act as an insulator to retain heat. Moreover, in a crevice configuration, the fabric surface contact with a smoldering cigarette is roughly twice that of flat configurations ${ }^{15}$.

This study reports on the smoldering propensity of commercially available BFs in a small-scale upholstered seating mock-up configuration. The focus is to rank the smoldering tendencies of different BFs. UFAC, ASTM, NFPA, BEARHFTI (Bureau of Electronic and Appliance Repair, Home Furnishings and Thermal Insulation), and the US Consumer Product Safety Commission (CPSC), have defined tests for barrier fabrics wherein a BF component is tested in similar mock-up configurations and pass/fail criteria based on CF char length, and/or mass loss of the components and/or of the complete mock-up assembly. This report provides insight into the quantitative properties of the BFs that define their smoldering propensity when used in combination with FPUF and CF. Existing test methods for assessing smoldering ignitability of a BF component in upholstered products are discussed in the following section.

\subsection{Existing test methods for assessing smoldering ignitability of BFs}

Various test methods that are used to assess smoldering ignitability of BFs are listed in Table 1. All test methods essentially require testing of a BF component interposed between FPUF and a smolder-prone cover fabric (Class II cover fabrics ${ }^{16}$ ). The smoldering ignition assessment of a barrier component, as described in the test methods listed in Table 1, is generally conducted on a small scale mock-up composite that is voluntarily used by many upholstered furniture and fabric manufacturers.

It should be noted that Cal TB $116,{ }^{17}$ ASTM $1352,{ }^{18}$ and NFPA $261^{19}$ require the use of real-scale mockups for smoldering ignition testing. The small-scale mock-up facilitates evaluation of smoldering propensity in multi-component systems of complex design. The mock-up consists of a wooden frame, upholstery components such as FPUF, BF, $\mathrm{CF}$, and a lit cigarette covered by a sheeting material. A covered cigarette smolders less intensely, increases the duration of glowing oxidation, and helps the cigarette burn completely, thereby increasing the likelihood of sustained smoldering of the FPUF substrate and the reproducibility of the test method ${ }^{20}$. The pass/fail criteria and the classification norms vary between the standardizing authorities. The barrier test method (Method $3^{21}$ ) defined by the UFAC, specifies a maximum allowable upward spread of smoldering, i.e., char length on the back cushion CF. The BF fails if there is an obvious smoldering ignition or the vertical char length on the CF exceeds $38 \mathrm{~mm}$ upward from the crevice $^{21}$. The BF passes the test only if it is capable of preventing charring of the CFs. The ASTM E1353 standard test method for cigarette ignition resistance of components of upholstered furniture ${ }^{22}$, classifies BFs based on a critical upward char length of $51 \mathrm{~mm}$ on the back CF. 
Table 1. Standards and test methods for assessing smoldering ignitability of BFs.

\begin{tabular}{|c|c|c|c|}
\hline $\begin{array}{l}\text { Issuing } \\
\text { authority }\end{array}$ & $\begin{array}{l}\text { Standard/Test } \\
\text { methods }\end{array}$ & Test specimen & Pass/fail/classification criteria. \\
\hline UFAC & $\begin{array}{l}\text { UFAC Method } 3^{21} \\
\text { Voluntary test methods }\end{array}$ & $\begin{array}{l}\text { Small-scale mock-up } \\
\text { Standard cotton velvet cover fabric and standard FPUF } \\
\text { substrate }\end{array}$ & - Vertical char length on $\mathrm{CF}<38 \mathrm{~mm}$. \\
\hline NFPA & $\begin{array}{l}\text { NFPA } 260^{23} \\
\text { Standard }\end{array}$ & $\begin{array}{l}\text { Small-scale mock-up } \\
\text { Standard cotton velvet cover fabric and standard FPUF } \\
\text { substrate }\end{array}$ & $\begin{array}{l}\text { - Class I barrier material: Vertical char length on CF } \\
\text { < } 51 \mathrm{~mm} \text {. } \\
\text { - Class II barrier material: Vertical char length on } \\
\text { CF }>51 \mathrm{~mm}\end{array}$ \\
\hline ASTM & $\begin{array}{l}\text { ASTM E } 1353^{22} \\
\text { Standard }\end{array}$ & $\begin{array}{l}\text { Small-scale mock-up } \\
\text { Standard cotton velvet cover fabric and standard FPUF } \\
\text { substrate }\end{array}$ & $\begin{array}{l}\text { - Class A barrier material: Vertical char length on } \\
\text { CF }<51 \mathrm{~mm} \text {. } \\
\text { - Class B barrier material: Vertical char length on } \\
\text { CF }>51 \mathrm{~mm} \text { or obvious smoldering ignition. }\end{array}$ \\
\hline ASTM & $\begin{array}{l}\text { ASTM D5238 } \\
\text { Standard test method } \\
\text { (now withdrawn) }\end{array}$ & Cotton battings & - Char length on $\mathrm{BF}<25.4 \mathrm{~mm}$ \\
\hline CPSC & $\begin{array}{l}16 \text { CFR Part1634 } \\
\text { (proposed) }^{25} \\
\text { Test method in proposed } \\
\text { federal regulation }\end{array}$ & $\begin{array}{l}\text { Small-scale mock-up } \\
\text { Standard cotton velvet cover fabric and standard FPUF } \\
\text { substrate }\end{array}$ & $\begin{array}{l}\text { - No transition to flaming during } 45 \text { min test } \\
\text { duration. } \\
\text { - FPUF mass loss }<1 \% \text {. }\end{array}$ \\
\hline BHFTI & $\begin{array}{l}\text { Cal TB } 117-2013^{9} \\
\text { Test method required in } \\
\text { the state of California. }\end{array}$ & Small-scale mock-up & $\begin{array}{l}\text { For BF to pass: } \\
\text { - No smoldering after the } 45 \mathrm{~min} \text { test duration. } \\
\text { - No transition to flaming during } 45 \mathrm{~min} \text { test } \\
\text { duration. } \\
\text { - } \text { Char length on } \mathrm{CF}<51 \mathrm{~mm} \text {. }\end{array}$ \\
\hline BHFTI & $\begin{array}{l}\text { Cal TB } 116^{17} \\
\text { Test method required in } \\
\text { the state of California. }\end{array}$ & Real-scale RUF & $\begin{array}{l}\text { - No transition to flaming during test duration. } \\
\text { - Char length on } \mathrm{CF}<51 \mathrm{~mm} \text {. }\end{array}$ \\
\hline
\end{tabular}


According to ASTM E1353, materials that develop char lengths of $51 \mathrm{~mm}$ or less on the CF are classified as Class A barriers and those which develop obvious ignition or have char lengths in excess of $51 \mathrm{~mm}$ are classified as Class B barriers. NFPA $260^{23}$ classifies barrier materials as Class I or II based on a char length similar to that prescribed by ASTM E1353. The most recent version of Cal TB 117-2013 ${ }^{9}$, also uses the vertical char length (ASTM E1353) criterion to assess smoldering tendency of barrier materials. A BF passes the test if the vertical char length on Type II CF is less than $51 \mathrm{~mm}$. A failure is recorded if the mock-up continues to smolder after the 45 min test duration or transitions to open-flaming. A Type II cover fabric is a smolder-prone cover fabric that fails the cover fabric test (without a barrier fabric) as described in Section 1 of Cal TB 117-2013 ${ }^{9}$. None of the test methods described above specifies measurement of the char length on the BF. Moreover, char length measurements tend to have poor reproducibility, and possible effects of textile structures, fiber content, and air permeability on smoldering combustion are uncertain. ${ }^{24}$ The BF smoldering resistance test described in the proposed CPSC 16 CFR part $1634^{25}$ is the only test method that uses mass loss of FPUF as its 'pass/fail' criterion. It is, therefore, the only test method that uses the smoldering behavior of the cushioning materials to characterize the smoldering behavior of a mock-up. The BF, when tested with a cotton velvet cover fabric (a smolderprone (Class II) fabric), passes the test if the mass loss of FPUF is less than $1 \%$ following the removal of any charred material and the mock-up does not transition to flaming during the 45 min test duration. This is a very stringent criterion as it requires minimal smoldering within the FPUF. This mass loss criterion provides a more quantitative characterization of FPUF smoldering ignition than the criteria described in the other test methods ${ }^{26}$.

ASTM had a barrier component test (now withdrawn) to assess the smoldering ignition resistance of cotton battings. In the ASTM D5238 ${ }^{27}$ test method, a lighted cigarette was placed between precut and preconditioned pieces of cotton battings and the length of the char was measured as soon as smoke was observed. This test method fails to specify the duration of testing. Failure was defined as char lengths of $25.4 \mathrm{~mm}$ or greater. This test method was often used by cotton batting manufacturers to spot check their products. This is a severe test as the ignition source is completely enclosed, permitting the cotton batting to act as an insulator to retain heat while being porous enough to allow adequate air flow to support smoldering combustion. Only boric acid-treated cotton battings generally passed this test. ${ }^{28}$

\section{Experimental Materials and Test Methods ${ }^{1}$}

A range of commercially available BFs were included in this study. The structural and physical properties of BFs such as mass per unit area (aerial density), bulk density, thickness, and air permeability were evaluated and are given in Table 2. For the purpose of this study, the mass per unit area is associated with the quantity of material available per unit area, while bulk density is related to the ability of oxygen to penetrate to ignition site. The exact fiber blend compositions are proprietary and thus were not available. No chemical analysis of barrier materials was made. The BFs varied in average thicknesses from $0.1 \mathrm{~mm}$ to $7.8 \mathrm{~mm}$.

\footnotetext{
${ }^{1}$ Certain commercial equipment, instruments or materials are identified in this paper in order to specify the experimental procedure adequately. Such identification is not intended to imply recommendation or endorsement by the National Institute of Standards and Technology, nor is it intended to imply that the materials or equipment identified are necessarily the best available for this purpose.
} 
Table 2. Description of BFs used in soft furnishings. Uncertainties are reported as Type A uncertainties ${ }^{49,50}$ with experimental standard deviations. Values are reported with $2 \sigma$ uncertainty

\begin{tabular}{|c|c|c|c|c|c|c|c|c|c|}
\hline \multirow{2}{*}{$\begin{array}{l}\text { Serial } \\
\text { No }\end{array}$} & \multirow{2}{*}{$\begin{array}{c}\text { Sample } \\
\text { code }\end{array}$} & \multirow[t]{2}{*}{ Fiber Blend } & \multirow[t]{2}{*}{ Structure } & \multirow[t]{2}{*}{ FR system } & \multirow{2}{*}{$\begin{array}{l}\text { Thickness, } \\
\text { mm }\end{array}$} & \multirow{2}{*}{$\begin{array}{c}\text { Area } \\
\text { Density, } \\
\mathbf{g}^{\prime} \mathbf{m}^{2}\end{array}$} & \multirow{2}{*}{$\begin{array}{c}\text { Bulk } \\
\text { Density, } \\
\text { g/cm³ }\end{array}$} & \multicolumn{2}{|c|}{ Air Permeability } \\
\hline & & & & & & & & CFM & $\mathrm{m} / \mathrm{s}$ \\
\hline 1 & BF-1 & FR rayon/polyester & Highloft & Passive & $4.1 \pm 0.1$ & 155 & 0.038 & $550 \pm 47$ & $2.8 \pm 0.2$ \\
\hline 2 & BF-2 & FR rayon/polyester & Highloft & Passive & $6.7 \pm 0.2$ & 230 & 0.034 & $339 \pm 18$ & $2.0 \pm 0.1$ \\
\hline 3 & BF-3 & FR rayon/polyester & Highloft & Passive & $7.8 \pm 0.6$ & 240 & 0.031 & $450 \pm 28$ & $2.3 \pm 0.1$ \\
\hline 4 & BF-4 & $\begin{array}{l}\text { Boric acid treated cotton/ FR } \\
\text { rayon/polyester }\end{array}$ & Stratified Highloft & Passive & $5.7 \pm 0.1$ & 230 & 0.040 & $428 \pm 52$ & $2.2 \pm 0.2$ \\
\hline 5 & BF-5 & Boric acid treated cotton & Highloft & Passive & $6.9 \pm 0.8$ & 230 & 0.033 & $\begin{array}{r}248 \pm \\
20 \\
\end{array}$ & $1.3 \pm 0.1$ \\
\hline 6 & BF-8 & FR rayon/polyester & $\begin{array}{l}\text { Needle punched } \\
\text { nonwoven }\end{array}$ & Passive & $4.3 \pm 0.1$ & 237 & 0.055 & $429 \pm 16$ & $2.2 \pm 0.1$ \\
\hline 7 & BF-9 & $\begin{array}{l}\text { FR rayon/polyester } \\
\text { (needlepunched) }\end{array}$ & $\begin{array}{l}\text { Needle punched } \\
\text { nonwoven }\end{array}$ & Passive & $2.2 \pm 0.1$ & 240 & 0.109 & $301 \pm 8$ & $1.5 \pm 0.1$ \\
\hline 8 & BF-10 & FR polyester /FR rayon & $\begin{array}{l}\text { Stitchbond } \\
\text { nonwoven }\end{array}$ & Active/Passive & $0.7 \pm 0.1$ & 165 & 0.236 & $212 \pm 13$ & $1.1 \pm 0.1$ \\
\hline 9 & BF-11 & $\begin{array}{l}\text { Glass fiber core/ FR acrylic } \\
\text { fiber (core spun yarn) }\end{array}$ & Knitted & Active & $0.9 \pm 0.1$ & 186 & 0.207 & $445 \pm 8$ & $2.3 \pm 0.1$ \\
\hline 10 & BF-12 & $\begin{array}{l}\text { Glass fiber core/ FR acrylic } \\
\text { fiber (core spun yarn) }\end{array}$ & Knitted & Active & $1.6 \pm 0.1$ & 237 & 0.148 & $564 \pm 8$ & $2.9 \pm 0.1$ \\
\hline 11 & BF-13 & $\begin{array}{l}\text { FR rayon/glass fiber/PLA } \\
\text { fiber (core spun yarn) }\end{array}$ & Knitted & Active & $1.4 \pm 0.1$ & 165 & 0.118 & $380 \pm 14$ & $1.9 \pm 0.1$ \\
\hline 12 & BF-15 & $\begin{array}{l}\text { Glass fiber core/ FR acrylic } \\
\text { fiber }\end{array}$ & Woven & Active & $0.5 \pm 0.1$ & 170 & 0.340 & $406 \pm 2$ & $2.1 \pm 0.1$ \\
\hline 13 & BF-16 & FR rayon/glass fiber/PLA & Nonwoven & Active & $2.9 \pm 0.1$ & 290 & 0.097 & $381 \pm 38$ & $1.9 \pm 0.2$ \\
\hline 14 & BF-17 & Glass fiber & Woven & Passive & $0.2 \pm 0.1$ & 150 & 0.750 & 0 & 0 \\
\hline 15 & BF-18 & Glass fiber & Woven & Passive & $0.1 \pm 0.1$ & 170 & 1.700 & 0 & 0 \\
\hline 16 & BF-19 & Glass fiber & Woven & Passive & $0.3 \pm 0.1$ & 320 & 1.067 & 0 & 0 \\
\hline 17 & BF-20 & Para-aramid/melamine & Woven & Passive & $0.77 \pm 0.02$ & 264 & 0.343 & $41 \pm 3$ & $0.2 \pm 0.1$ \\
\hline 18 & BF-21 & Para-aramid & Nonwoven & Passive & $0.67 \pm 0.02$ & 69 & 0.103 & $414 \pm 15$ & $2.1 \pm 0.1$ \\
\hline 19 & BF-22 & Meta aramid/para aramid & $\begin{array}{l}\text { Woven/nonwoven } \\
\text { composite }\end{array}$ & Passive & $1.61 \pm 0.11$ & 267 & 0.166 & $187 \pm 27$ & $0.9 \pm 0.1$ \\
\hline 20 & BF-23 & Cotton/glass fiber & $\begin{array}{l}\text { Knitted/ } \\
\text { backcoated }\end{array}$ & Active/Passive & $1.5 \pm 0.1$ & 284 & 0.189 & 0 & 0 \\
\hline
\end{tabular}


The air permeability of components in upholstered products is known to have a significant effect on their smoldering propensity. ${ }^{20,29}$ Air permeability is described as the rate of air flow passing perpendicularly through a known area, under a prescribed air pressure differential between the two surfaces of the material. Air permeabilities of BFs were measured using an electronic high differential pressure air permeabilitymeasuring instrument (FAP 5352 F2, Frazier Precision Instrument Co. Inc., Hagerstown, MD). ${ }^{30}$ The air pressure differential between the two surfaces of the material was set to $125 \mathrm{~Pa}$ (13 mm of water). Fabrics were clamped in a circular specimen holder, exposing $6.45 \mathrm{~cm}^{2}$ to the perpendicular air flow. Nozzles with orifice diameters of $2.0 \mathrm{~mm}, 3.0 \mathrm{~mm}$, and $6.0 \mathrm{~mm}$ were used in order to reach the target pressure drop (125 $\mathrm{Pa})$. The value of permeability $(\phi)$ in terms of volumetric air flow was read in cubic feet of air per square foot of sample area per minute (CFM) at about $20{ }^{\circ} \mathrm{C}$ and 1 atm and was converted to cubic meters per square meter of sample per second or simply meters per second) at a temperature of $20{ }^{\circ} \mathrm{C}$ and atmospheric pressure of $100 \mathrm{kPa}$. Ten readings were taken for each of the BFs and calculated averages are reported.

The smoldering tendencies of BFs were studied in two different experiments. First, a smoldering cigarette was used as an ignition source to initiate smolder directly in the BF. The second set of experiments was designed to determine the ability of a BF to act as a smoldering ignition source of FPUF. The smoldering propensity of a $\mathrm{BF}$ in the presence of a smolder-prone cover fabric was tested using the test method described in CPSC's proposed standard 16 CFR $1634,{ }^{25}$ which is an adaptation of the UFAC Test Method 3. ${ }^{16}$ The test method is designed to assess the barrier performance when placed between a smolder-prone cover fabric and a FPUF substrate. The test method essentially evaluates the likelihood of FPUF smoldering in the presence of a BF. The mock-up consists of a wooden frame, a FPUF, BF, cover fabric, and a lit cigarette under a sheeting material. Note that it has recently been shown that such mock-up assemblies where the vertical (back) and horizontal (seat) pieces of FPUF are pressed tightly against the wood frame $e^{9,16,18,25}$ do not smolder as readily as mock-ups which are raised above the wooden frame and have greater access to the surrounding air. ${ }^{29}$

Smoldering behavior may be examined in several ways, depending on whether it is characterized by smoldering temperatures, smoldering times, char lengths, char areas, or mass loss. ${ }^{31}$ For the purpose of this study, we considered the mass loss of the complete mock-up assembly and the fraction of the FPUF used in the mock-up assembly which smoldered during a set time period. Rate of mass loss is reported in this study and has been previously used by Damant et $\mathrm{al}^{24}$ to evaluate the smoldering propensity of upholstery fabrics under conditions of cigarette ignition. Char length measurements on the BFs are also reported. Char lengths on the CFs are not reported since different standards prescribe different methods of measuring char lengths as described earlier.

All materials were conditioned, specimens were assembled, and tests were performed at a relative humidity $(\mathrm{RH})$ of $55 \% \pm 5 \%$ and a temperature of $22{ }^{\circ} \mathrm{C} \pm 3{ }^{\circ} \mathrm{C}$. A detailed description of the equipment used for maintaining these environmental conditions is available elsewhere. ${ }^{32}$ The FPUF foam used in this study was a well characterized flexible polyurethane foam ${ }^{32}$ especially developed for evaluating upholstery materials and their tendency to support smoldering or limit flaming combustion. ${ }^{33}$

The masses of the vertical $(203 \times 203 \times 76) \mathrm{mm}^{3}$ and horizontal $(127 \times 203 \times 76) \mathrm{mm}^{3} \mathrm{FPUF}$ sections were recorded and used later to calculate the fraction that smoldered. The FPUF was covered with the BF, and, in turn, by the cover fabric (Indigo Buckaroo Denim purchased from Jo Ann Fabrics was used in this study), and the entire ensemble was placed in the wooden frame. The $100 \%$ cotton $\mathrm{CF}$ had an average aerial density of $445 \mathrm{~g} / \mathrm{m}^{2} \pm 3 \mathrm{~g} / \mathrm{m}^{2}$ and air permeability of $0.10 \mathrm{~m} / \mathrm{s} \pm 0.02 \mathrm{~m} / \mathrm{s}$. The BF and the cover fabric were 
carefully placed over the FPUF, and particular attention was paid to avoid formation of any air pockets between layers since such pockets tend to behave as insulators and can result in poor reproducibility. ${ }^{34}$ The complete mock-up assembly along with the specimen holder was placed on a mass balance accurate to \pm $0.01 \mathrm{~g}$ within the normal operating environment of the laboratory used for material conditioning, sample assembly, and sample testing. The smoldering ignition test was carried out inside a poly(methyl methacrylate) enclosure, in order to prevent excessive changes in surface ventilation, located under a laboratory canopy-type hood. A lighted cigarette (Standard Cigarette for Ignition Resistance Testing, NIST SRM 1196) ${ }^{35}$ was placed in the crevice formed by the intersection of the vertical (back) and horizontal (seat) panels of each test assembly. Each cigarette was covered with a piece of sheeting fabric (UF-400; Testfabrics, Inc.; West Pittston, PA, USA.), a $100 \%$ cotton, white plain weave with 19 threads/ $\mathrm{cm}^{2}$ to 33 threads $/ \mathrm{cm}^{2}$, and an aerial density of $115 \mathrm{~g} / \mathrm{m}^{2} \pm 1 \mathrm{~g} / \mathrm{m}^{2}$. The cigarette was allowed to burn its entire length $(82 \mathrm{~mm})$. Three specimens were tested for each barrier fabric.

The real-time mass of the complete assembly was recorded manually every two min. After the 45 min test duration, the FPUF (char and non-char) was separated from the other test components (e.g., cigarette ash, $\mathrm{CF}$ and $\mathrm{BF}$ ), and the mass of this FPUF was measured. The char was then removed and the mass of the remaining non-charred foam was measured. The smoldering mass loss ratio was calculated as the difference between the non-charred FPUF mass and the original FPUF mass divided by the original FPUF mass. ${ }^{25}$ The percent mass loss of FPUF was defined by Zammarano et $\mathrm{al}^{29}$ as the char volume fraction (CVF). They assumed that the density of virgin FPUF was homogeneous and did not vary during the test. They also showed that the $\mathrm{CVF}$ is proportional to the average volumetric rate of smoldering propagation during the test and was, therefore, used in this work as a measure of the average smoldering propagation rate.

\section{Results and Discussion}

\subsection{Cigarette-induced FPUF smolder}

The cigarette-induced smoldering behavior of bare FPUF was tested in the mock-up configuration. A lit cigarette was placed in the crevice of the mock-up assembly and was covered with a sheeting material. It was found that the FPUF used in this study did not develop self-sustained smoldering (visually identified as continued production of smoke after the extinguishment of the ignition source). This is in agreement with earlier studies where flexible polyurethane foam had shown good resistance to sustained smoldering in the presence of a smoldering cigarette. ${ }^{29,36,37}$ Although the cigarettes burned their entire length, leaving behind a grey ash, the CVF for SRM foams was only $0.3 \% \pm 0.1 \%$. A minimal thermal decomposition of FPUF was noted. The cellular structure of FPUF in the immediate vicinity of smoldering cigarette collapsed forming a tar-like liquid instead of a porous char. It is appears that the FPUF followed the non-oxidative pathway prompted by an increase in heating rate in the presence of the smoldering cigarette ${ }^{29}$. Once the cellular structure, essential for smolder propagation, had collapsed, the thermal influence of the smoldering cigarette over the FPUF was lost. The loss of thermal contact with the smoldering ignition source led to smolder suppression. Previous studies ${ }^{38}$ have also shown that the rate of heat generated in the smoldering process is related to the size of the smoldering zone. Thus, localized thermal decomposition in FPUF caused by a smoldering cigarette was not sufficient to develop self-sustained smoldering in the FPUF. By definition, self-sustained smoldering occurs when the smoldering front has extended to a region beyond the thermal influence of the ignition source. ${ }^{29}$ 


\subsection{Cigarette-induced BF smolder}

The cigarette-induced smoldering behavior of BFs was tested in a small-scale mock-up configuration with FPUF/BF composites. The main purpose of these experiments was to determine whether or not the intensity of heat flux from a smoldering cigarette in combination with a given BF was sufficient to initiate sustained smoldering in the FPUF. The SRM cigarette used in this study smolders with sufficient heat flux intensity to form char in some of the adjacent BF layers. However, none of the BFs evaluated in this study resulted in self-sustained smoldering in the FPUF. The insulating properties of charring BFs placed immediately under the glowing cigarette may cause excessive heat losses near the smoldering front, leading to extinguishment of smoldering within the BF layer. The mass loss of complete assemblies and the CVF of FPUF during these smoldering ignition tests were negligible and, hence, are not reported.

Typical digital images of the char formed and the measured char lengths on the BFs during these tests are shown in Table 3. Generally, most test methods discussed earlier require measurement of vertical char length from the crevice or length of char from the nearest point of the original location of the cigarette. In this study however, full length of char on the BFs are reported. Except for charring in the immediate vicinity of the cigarettes, the BFs remained intact and undamaged. Air permeability levels, fiber blends, and fabric structures had no significant effect on char areas on the BFs. Thus, BFs did not develop significant smoldering when placed in direct contact with the cigarette i.e., the heat flux from a smoldering cigarette was not sufficient to induce sustained smoldering in the BFs or the underlying FPUF.

\subsection{Cover fabric-induced FPUF smolder}

The real-time mass-loss and mass loss rate curves for FPUF covered only by the CF are shown in Figure 1(a) and Figure 1(b). It can be noted from Figure 1(a) that the mock-up assemblies did not begin to lose significant mass until almost 12 min from the start of the test. The smoldering process intensified as the cigarette burned, generating additional heat as more of the $\mathrm{CF}$ began to smolder. As the smolder front propagated laterally and downward into the crevice, the mass loss rate increased. At around 25 min - 28 min into the test, the cigarette had burned completely; by this time the CF had become a self-sustained smoldering ignition source. At $35 \mathrm{~min}$, the mock-up assembly mass loss rate began to rapidly increase (see Figure 1 (b)) indicating the start of sustained smoldering of the mock-up. ${ }^{29,32}$ From temperature measurements using thermocouples, Zammarano et al. established that the smoldering front reaches depth in the FPUF, where the heat losses are minimal and smoldering is likely to be self-sustained. Based on previous studies on smoldering of FPUF, ${ }^{29,32,39}$ we propose that the acceleration in mass loss of the complete mock-up assembly occurs when the smoldering front has reached a depth in the FPUF where char oxidation becomes dominant. 
Table 3. Digital images and char lengths of charred BFs tested in a mock-up configuration with and without smolder-prone CF

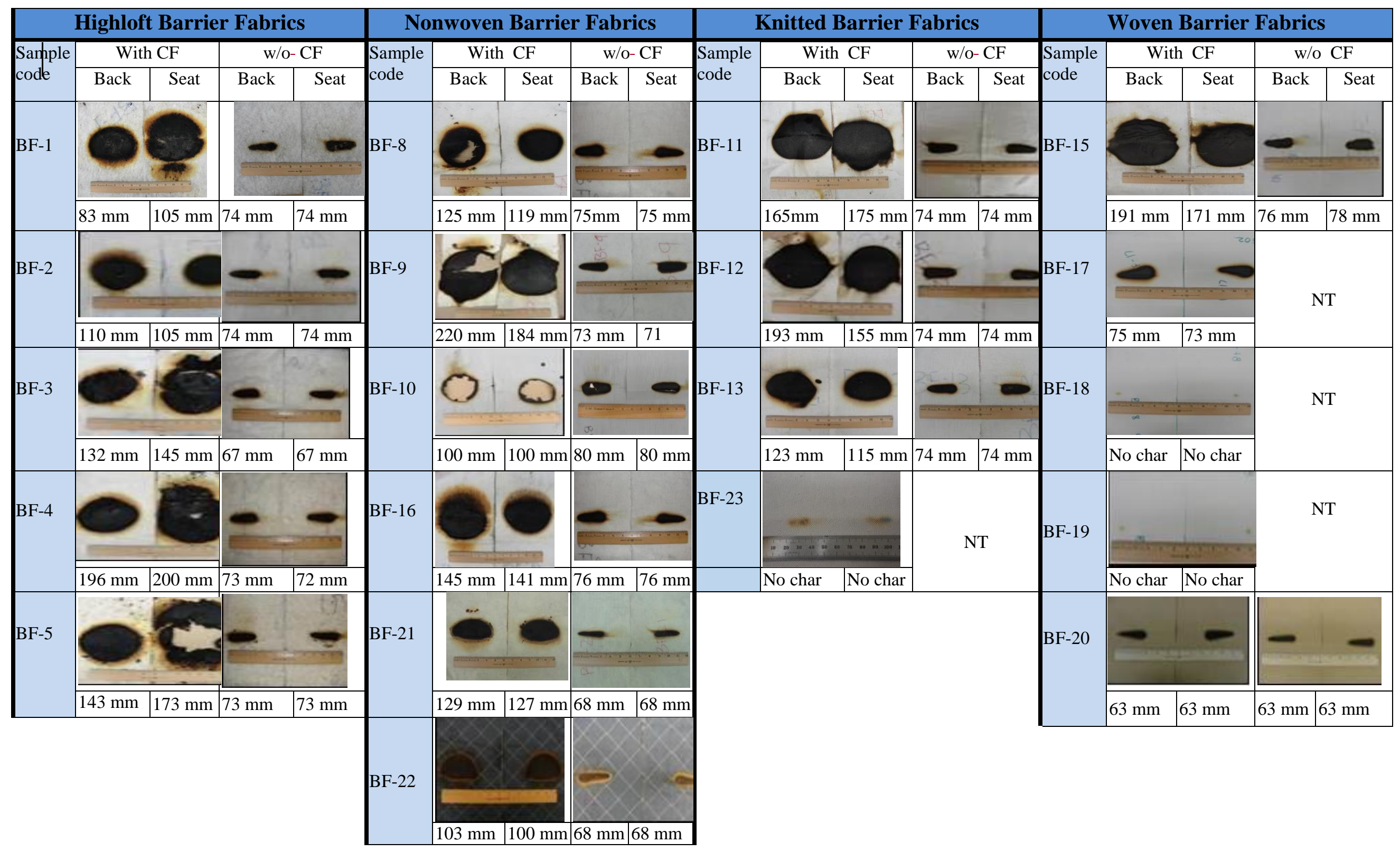



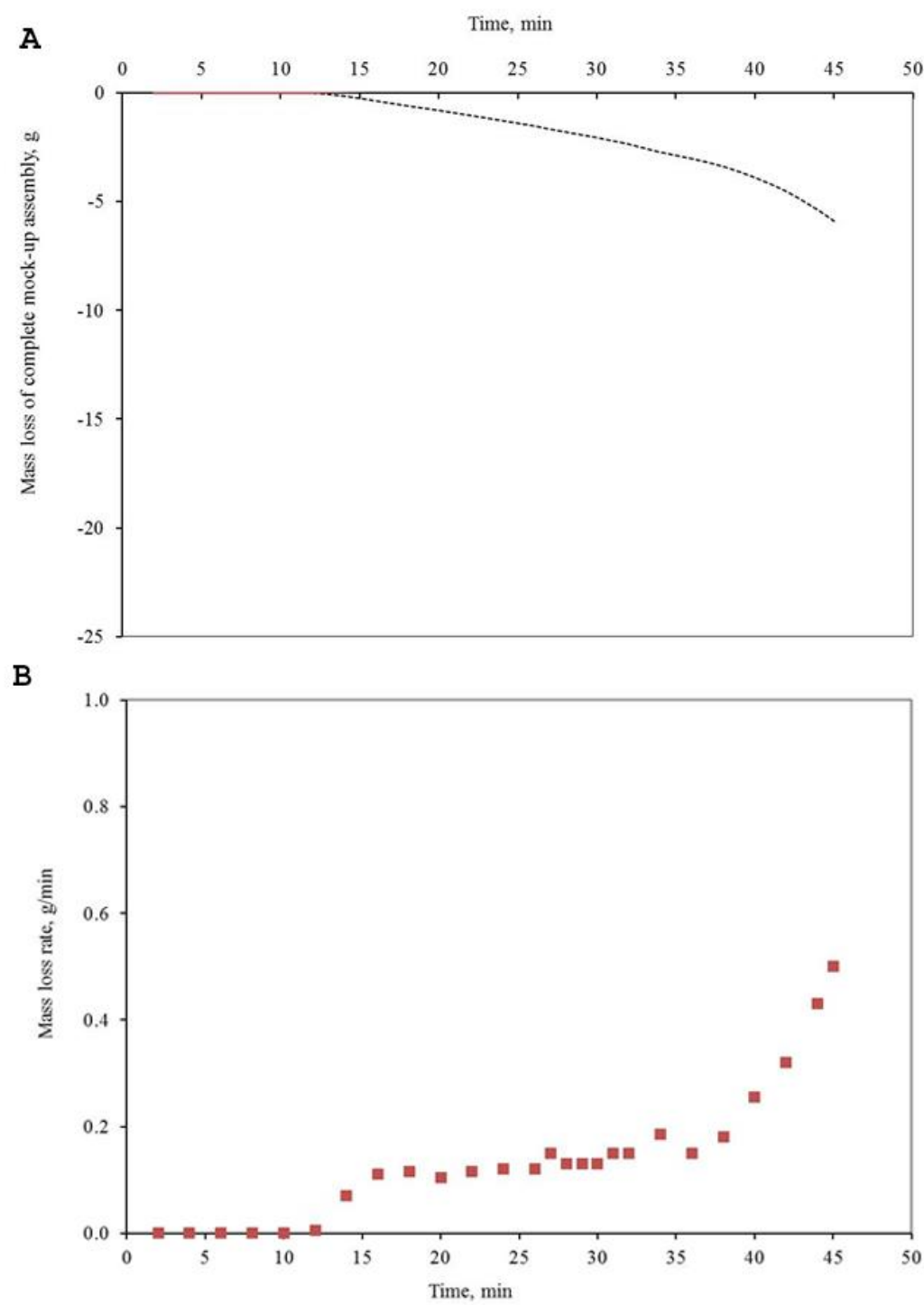

Figure 1. Real-time mass loss (A) and mass loss rate (B) curves for a FPUF/CF mock-up assembly.

At 45 min, the test was terminated, and the CVF was determined as described in the experimental section. The CVF for the FPUF was $10 \% \pm 5 \%$ and the maximum char lengths on the seat and back CFs were measured as $100 \mathrm{~mm} \pm 2 \mathrm{~mm}$. The development of smoldering and the extent of char in the FPUF as a function of time was characterized by stopping the tests after $15 \mathrm{~min}, 30 \mathrm{~min}$, and $45 \mathrm{~min}$. Results are shown in Table 4. The rapid growth of the CVF over the $30 \mathrm{~min}$ period is evident. 
Table 4. Digital images of FPUF/CF mock-up assemblies and char damage on FPUF at the end of 15 min, $30 \mathrm{~min}$, and $45 \mathrm{~min}$ test durations

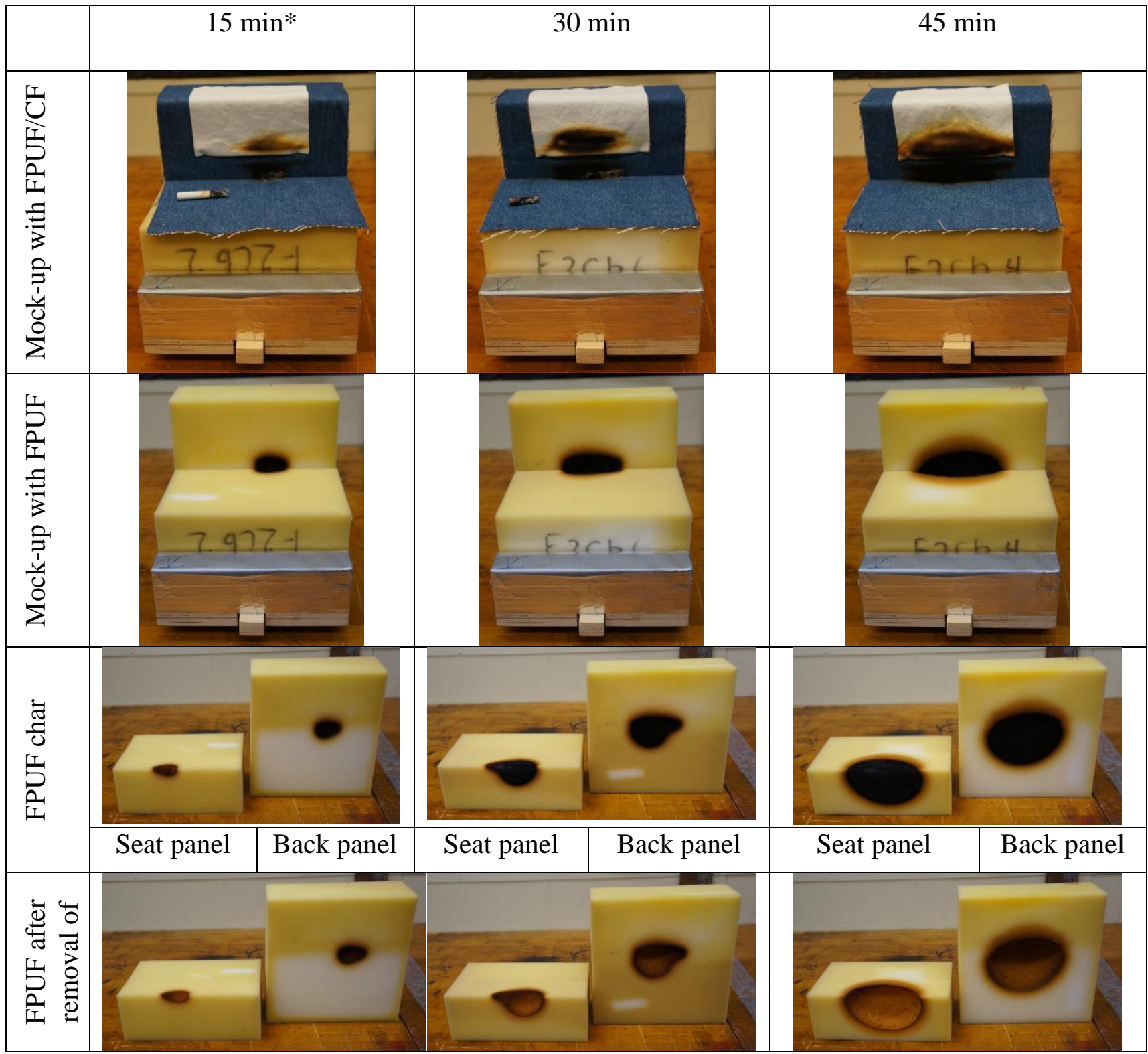

*For clarity, the cigarette has been removed from the crevice.

The results indicate that this smolder-prone CF and FPUF combination has a significant propensity to develop smoldering when in contact with a lit cigarette. Smoldering ignition of $100 \%$ cellulosic CFs in combination with FPUF has been widely reported. ${ }^{20,24,26,34,42}$ A smoldering cigarette produces sufficient heat to prompt thermal degradation in the cellulosic $\mathrm{CF}$, followed by formation of a carbonaceous char.

In presence of oxygen, this carbonaceous char undergoes further oxidation and produces more heat. This excess heat is dissipated in the underlying FPUF and in part lost to the immediate surrounding atmosphere. The thermal degradation of FPUF in air starts at around $270{ }^{\circ} \mathrm{C}$ to $295{ }^{\circ} \mathrm{C}^{40}$ and is the result of two competitive decomposition pathways: an oxidative pathway which produces a charred foam-like residue 
and a non-oxidative pyrolysis which generates liquid tar. The higher the likelihood of char formation, the greater will be the likelihood of the development of sustained smoldering. ${ }^{15}$ A higher rate of char formation in a smolder-prone cover fabric is thus manifested in a higher smoldering propensity of FPUF. Furthermore, the shape of the cavities formed due to smoldering in FPUF (see FPUF images in Table 4) suggest a "concave" smolder front geometry. As pointed out by Ohlemiller, ${ }^{41}$ the increasingly "concave" smolder front geometry reduces radiative heat losses to the surroundings leading to sustained smoldering in the FPUF.

\subsection{Cover fabric-induced BF smolder}

The potential contribution of BFs to the smoldering ignition of FPUF was also studied for BFs covered by a smolder-prone cover fabric $(\mathrm{CF})$. In order to assess the protective effectiveness of a $\mathrm{BF}$, the smoldering behavior of the FPUF covered by both a BF and CF was characterized by recording the real-time massloss of mock-ups, BF char lengths, and char volume fraction (CVF) of FPUF. The mass loss curves for complete mock-up assemblies (FPUF/BF/CF) incorporating various BFs are shown in Figure 2.

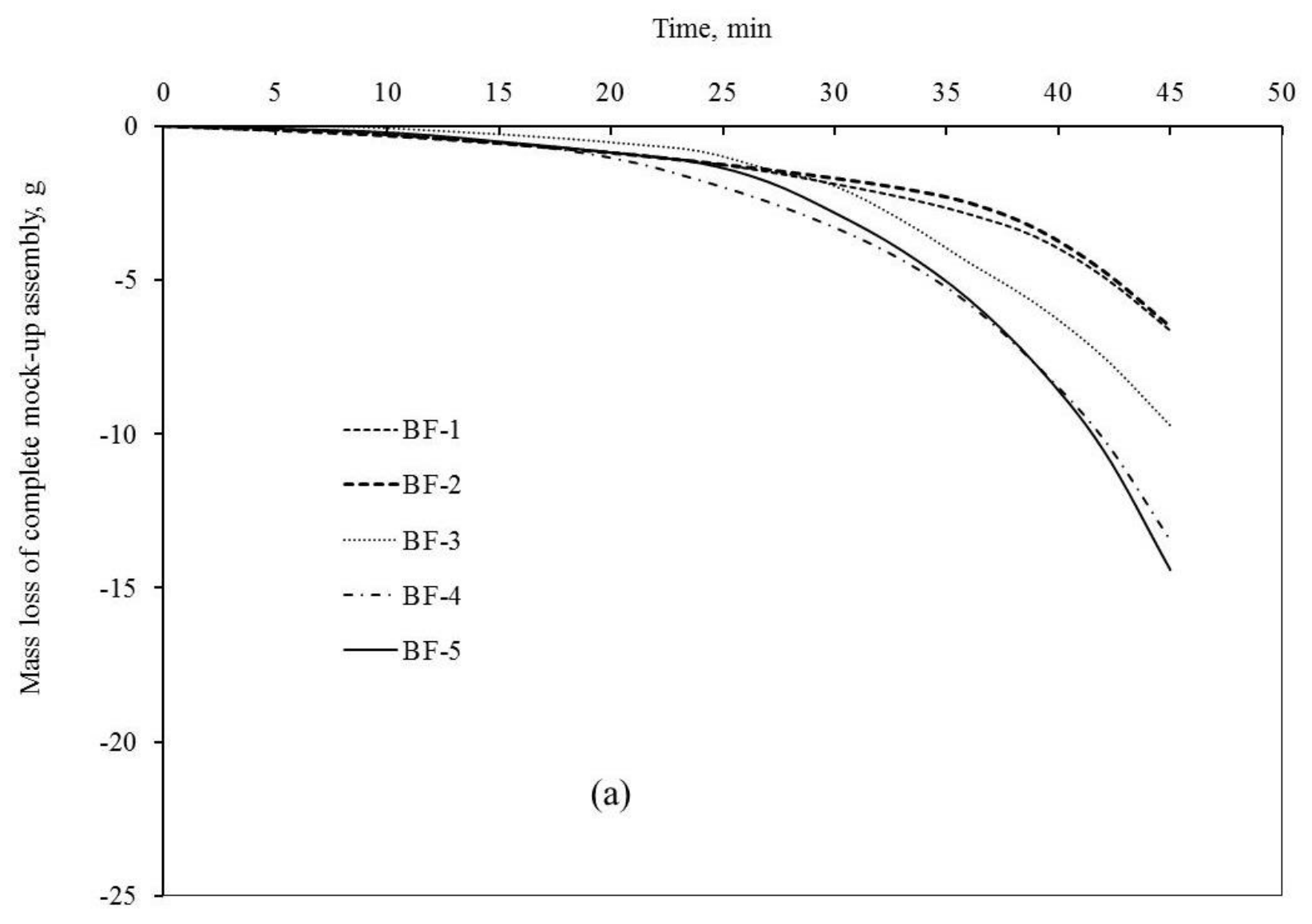


Time, $\min$
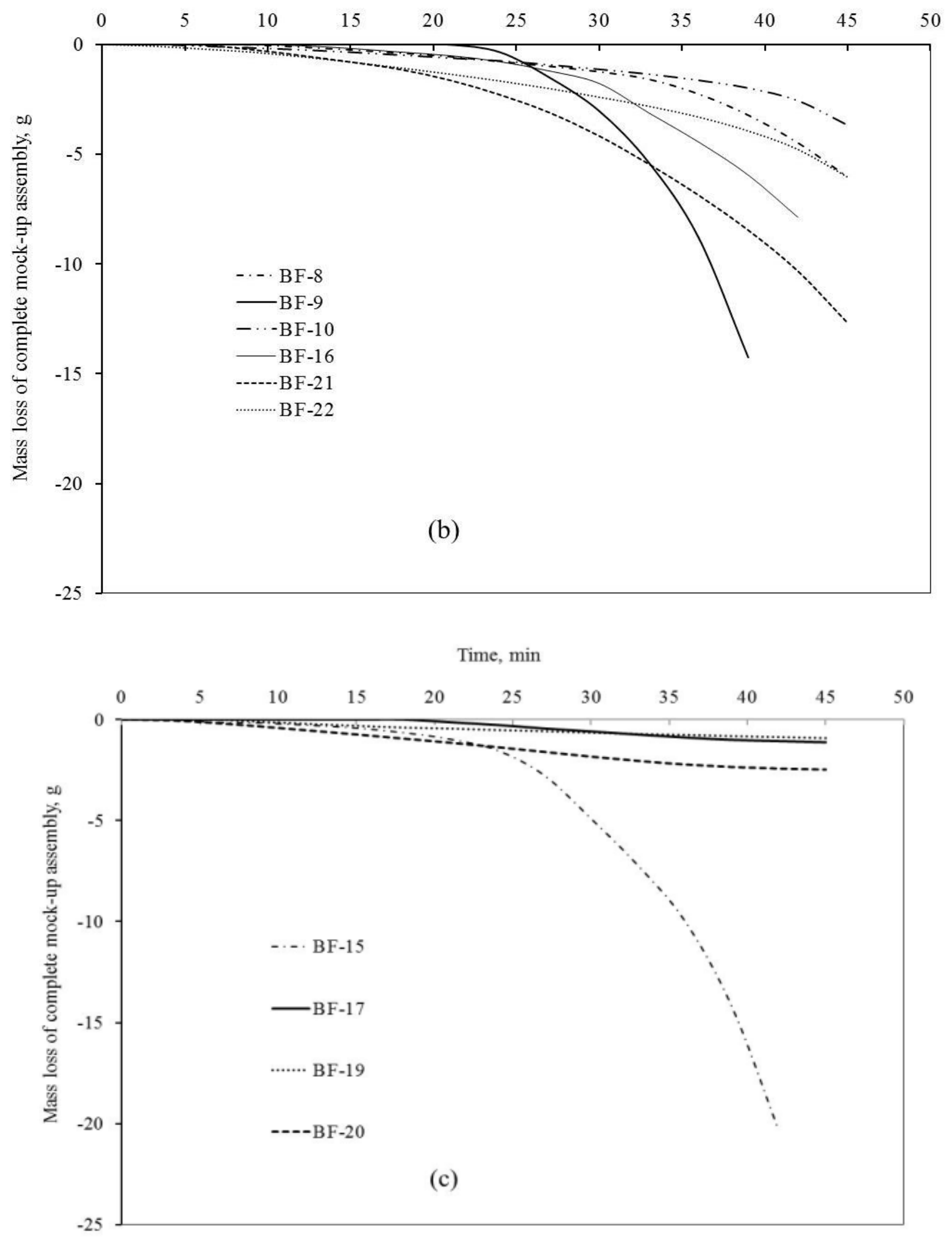


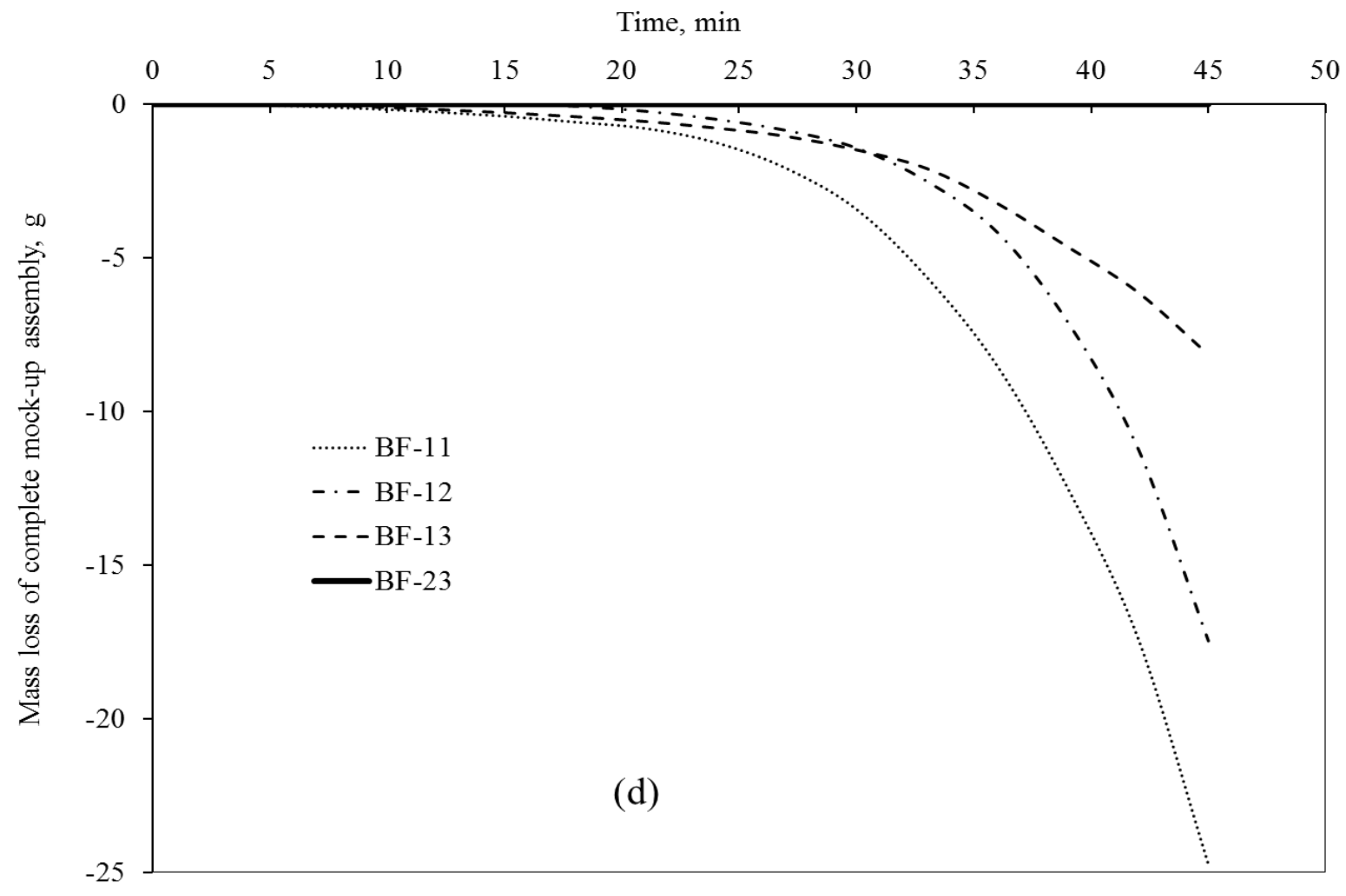

Figure 2. Real-time percent mass loss of complete mock-up assemblies during smoldering ignition resistance tests for: (a) highloft, (b) nonwoven, (c) woven, and (d) knitted barrier materials.

The mass loss data in Table 5 show that the smolder-prone CF when placed on top of a number of the BFs was capable of releasing sufficient heat to initiate smoldering and subsequently transmit the heat to the underlying FPUF. 
Table 5. Mass loss, CVF and derived indices from smoldering ignition resistance test for FPUF/BF/CF composites. Uncertainties are Type A uncertainties ${ }^{49,50}$ based on experimental standard deviations. Values are reported as $2 \sigma$ (i.e, coverage factor of $95 \%$ ).

\begin{tabular}{|c|c|c|c|c|c|c|c|c|c|c|c|}
\hline \multirow{3}{*}{$\begin{array}{l}\text { Sample } \\
\text { code }\end{array}$} & \multirow{3}{*}{$\begin{array}{l}\text { Initial } \\
\text { Mass", } \\
\quad \text { g }\end{array}$} & \multirow{2}{*}{\multicolumn{5}{|c|}{$\begin{array}{l}\text { Mass loss for complete assembly (gaseous mass } \\
\text { loss), } \mathrm{g}\end{array}$}} & \multicolumn{3}{|c|}{ Char volume fraction (CVF), \% } & \multirow{3}{*}{$\begin{array}{c}\text { BF } \\
\text { smoldering } \\
\text { index }\end{array}$} & \multirow{3}{*}{$\begin{array}{c}\text { Pass/Fail } \\
\text { classification }\end{array}$} \\
\hline & & & & & & & \multirow{2}{*}{$\begin{array}{l}\text { Avg. } \\
\text { Foam }\end{array}$} & \multirow{2}{*}{$\begin{array}{l}\text { Back } \\
\text { Foam }\end{array}$} & \multirow{2}{*}{$\begin{array}{c}\text { Seat } \\
\text { Foam }\end{array}$} & & \\
\hline & & $20 \mathrm{~min}$ & $30 \mathrm{~min}$ & $40 \mathrm{~min}$ & $45 \mathrm{~min}$ & Avg.. \% & & & & & \\
\hline No BF & 221 & 0.91 & 2.06 & 3.90 & $6 \pm 2$ & 3 & $10 \pm 5$ & $9 \pm 4$ & $12 \pm 5$ & - & - \\
\hline $\mathrm{BF}-1$ & 255 & 0.91 & 1.88 & 3.33 & $7 \pm 5$ & 3 & $17 \pm 13$ & $13 \pm 10$ & $24 \pm 18$ & 1.7 & Fail \\
\hline $\mathrm{BF}-2$ & 266 & 0.93 & 1.69 & 3.33 & $7 \pm 5$ & 3 & $17 \pm 8$ & $13 \pm 6$ & $22 \pm 13$ & 1.7 & Fail \\
\hline BF-3 & 269 & 0.59 & 1.94 & 5.77 & $10 \pm 3$ & 4 & $22 \pm 5$ & $18 \pm 3$ & $30 \pm 8$ & 2.2 & Fail \\
\hline $\mathrm{BF}-4$ & 272 & 1.18 & 3.29 & 7.75 & $13 \pm 6$ & 5 & $33 \pm 14$ & $25 \pm 10$ & $45 \pm 19$ & 3.3 & Fail \\
\hline BF-5 & 295 & 0.93 & 2.82 & 7.75 & $14 \pm 4$ & 5 & $34 \pm 8$ & $23 \pm 2$ & $51 \pm 17$ & 3.4 & Fail \\
\hline BF-8 & 267 & 0.55 & 1.24 & 3.32 & $6 \pm 4$ & 2 & $16 \pm 7$ & $12 \pm 5$ & $21 \pm 9$ & 1.6 & Fail \\
\hline BF-9 & 255 & 0.01 & 30.0 & 14.26 & $31 \pm 2$ & 12 & $<50$ & $<50$ & $<50$ & $<5.0$ & Fail \\
\hline BF-10 & 253 & 0.62 & 1.13 & 1.98 & $4 \pm 4$ & 2 & $11 \pm 6$ & $9 \pm 5$ & $15 \pm 7$ & 1.1 & Fail \\
\hline BF-11 & 258 & 0.79 & 3.42 & 12.50 & $25 \pm 5$ & 10 & $47 \pm 11$ & $42 \pm 9$ & $51 \pm 13$ & 4.7 & Fail \\
\hline BF-12 & 274 & 0.23 & 1.43 & 7.09 & $\begin{array}{c}17 \pm \\
13\end{array}$ & 6 & $35 \pm 21$ & $31 \pm 20$ & $42 \pm 24$ & 3.5 & Fail \\
\hline BF-13 & 281 & 0.56 & 1.49 & 4.64 & $8 \pm 4$ & 3 & $17 \pm 8$ & $15 \pm 6$ & $20 \pm 11$ & 1.7 & Fail \\
\hline BF-15 & 253 & 0.98 & 4.91 & 14.21 & $\begin{array}{c}29 \pm \\
10\end{array}$ & 11 & $50 \pm 22$ & $45 \pm 21$ & $58 \pm 24$ & 5.0 & Fail \\
\hline BF-16 & 275 & 0.51 & 3.12 & 5.95 & $9 \pm 5$ & 3 & $22 \pm 9$ & $19 \pm 7$ & $26 \pm 12$ & 2.2 & Fail \\
\hline BF-21 & 233 & 1.63 & 4.17 & 8.46 & $13 \pm 3$ & 5 & $24 \pm 1$ & $21 \pm 5$ & $29 \pm 8$ & 2.4 & Fail \\
\hline BF-22 & 267 & 1.35 & 2.40 & 3.94 & $6 \pm 4$ & 2 & $13 \pm 3$ & $11 \pm 2$ & $16 \pm 4$ & 1.3 & Fail \\
\hline BF-17 & 253 & 0 & 0.50 & 1.01 & $1 \pm 0.5$ & 0 & 0 & 0 & 0 & 0.0 & Pass \\
\hline BF-18 & 253 & 0 & 0 & 0 & $0 \pm 0$ & 0 & 0 & 0 & 0 & 0.0 & Pass \\
\hline BF-19 & 277 & 0 & 0.65 & 0.82 & $1 \pm 0.5$ & 0 & 0 & 0 & 0 & 0.0 & Pass \\
\hline BF-20 & 271 & 1.15 & 1.84 & 2.35 & $2 \pm 1$ & 1 & 0.6 & 0 & 0 & 0.0 & Pass \\
\hline BF-23 & 319 & 0 & 0 & 0 & 0 & 0 & 0 & 0 & 0 & 0.0 & Pass \\
\hline
\end{tabular}

* Initial mass of mock-up components excluding wooden frame. Wooden frames weigh @ $1300 \pm 20 \mathrm{~g}$.

$\S$ Pass/fail classification based on CPSC's 16 CFR 1634 proposed rule ${ }^{25}$. 
The CVFs for mock-ups incorporating various BFs are shown in Figure 3. The average CVF at the end of a 45 min test depended on the smoldering propensity; which depended on the BF structure, fiber content, air permeability, and bulk density; of a given BF. The lower the smoldering propensity of the BF, the less likely was the development of sustained smoldering in the FPUF. The impact of a BF on smoldering likelihood of FPUF can be characterized in terms of changes in the CVF for mock-ups tested with and without a BF. Results are shown in Figure 4 as the CVF observed with the CF only minus the value for tests when a $\mathrm{BF}$ was included. Positive values indicate that the $\mathrm{BF} / \mathrm{CF}$ combination resulted in reduced FPUF smoldering as compared to using the CF alone. Similarly, negative values indicate increased smoldering with the BF/CF combination.

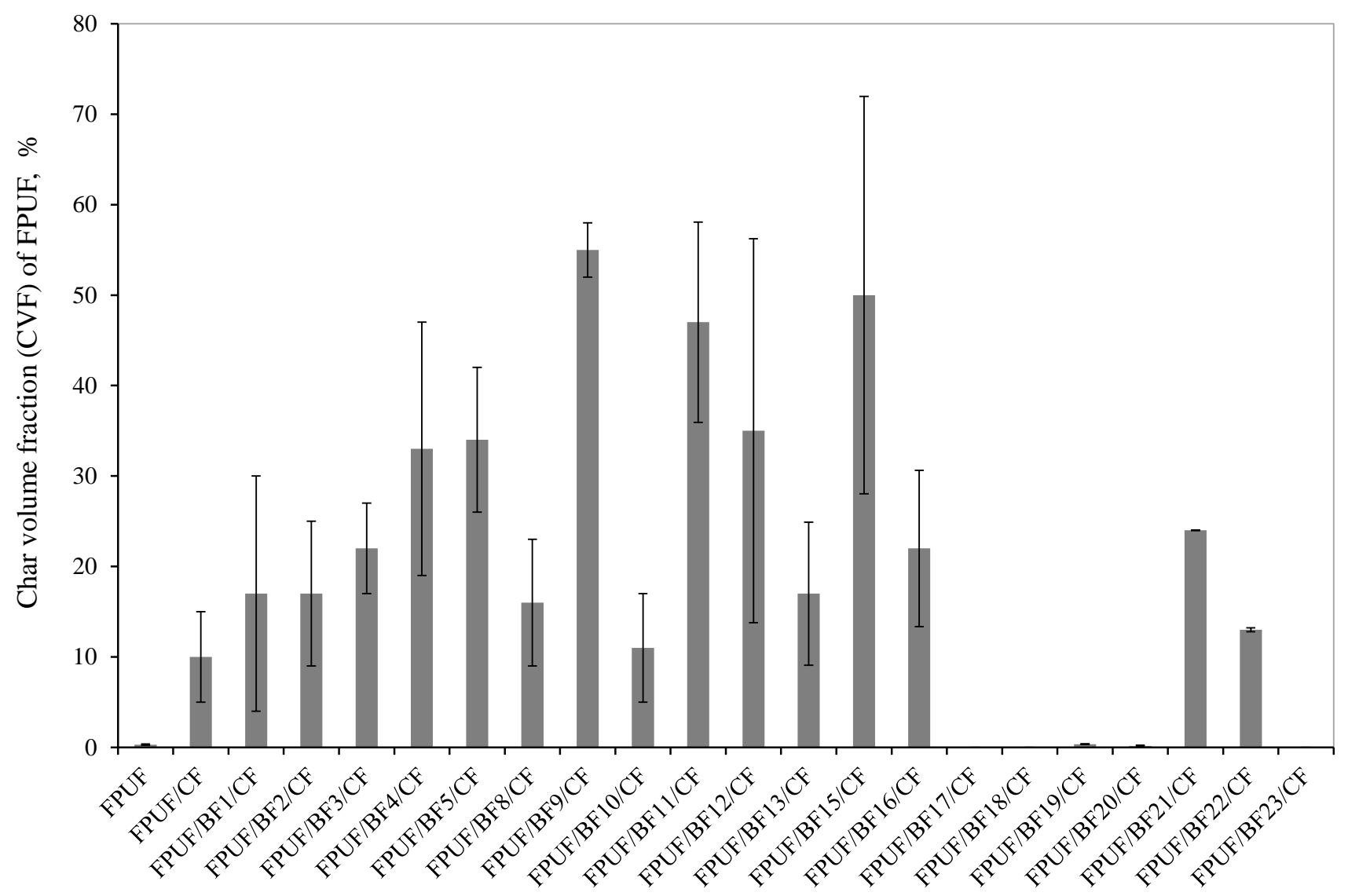

Figure 3. Char volume fraction (CVF) of FPUF during smoldering ignition resistance test for BFs in the presence of a smolder-prone cover fabric. 


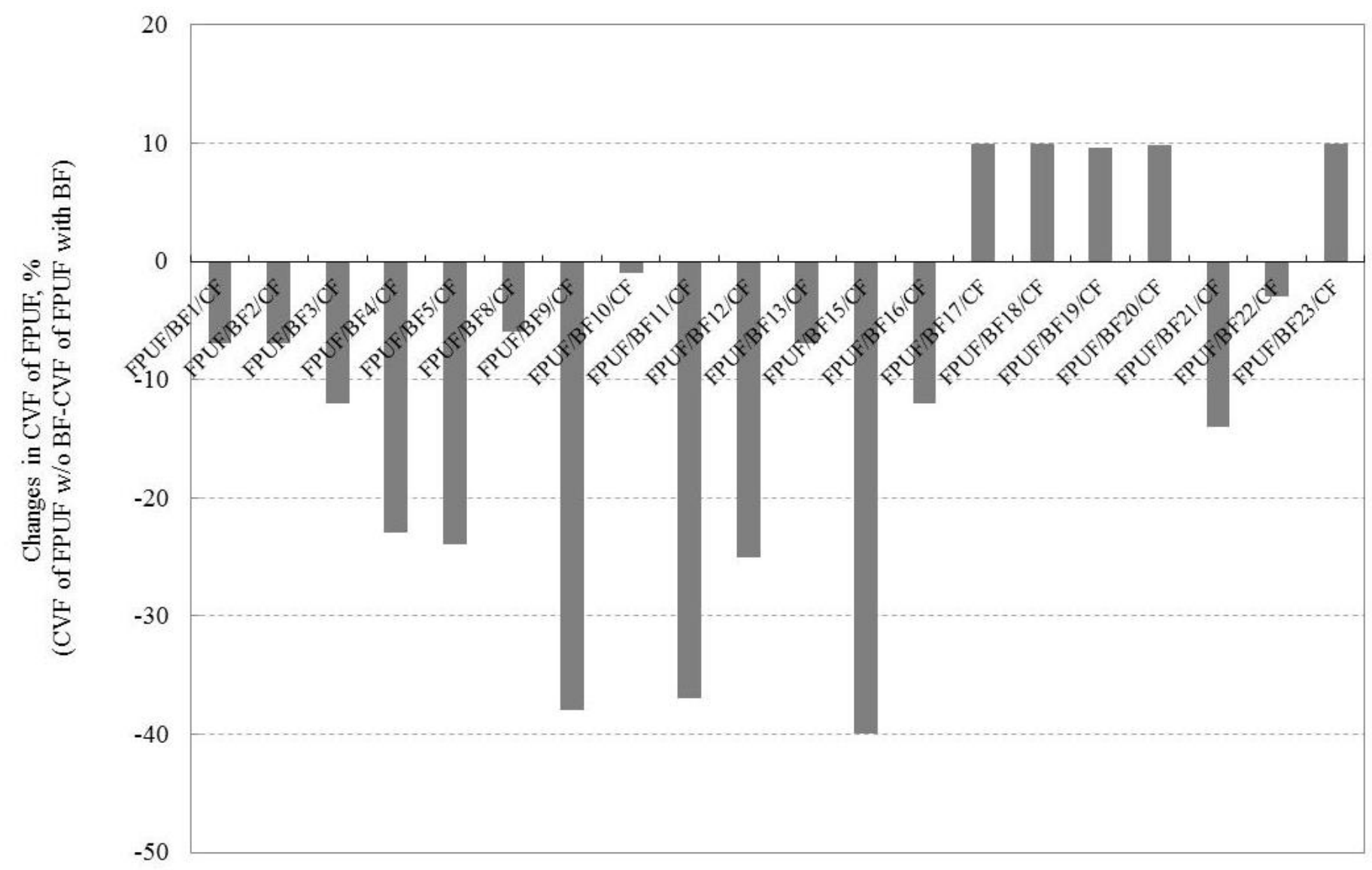

Figure 4. Relative changes in char volume fraction (CVF) of FPUF with and without BFs.

CVFs for FPUF/BF/CF combinations normalized by the CVF for the FPUF/CF combination provide a quantitative measure for the relative propensity of BFs to induce smoldering in FPUF and will be referred to as the smoldering index. The smoldering indices for various BFs are given in Table 5. Zero or close to zero values correspond to cases where the FPUF is protected by the BF, and sustained smoldering does not develop. BFs with smoldering index of 1 or more resulted in self-sustained smoldering in the FPUF. It is possible to get sustained smoldering for an smoldering index of less than one, but the smoldering would be less intense than without the BF.

In some cases (BF-18, BF-19 and BF-23), the cigarettes self-extinguished in less than 6 min and in others (BF-17 and BF-20), the observed burning rate was unusually slow. It is important to note that the burning behavior of a cigarette is known to vary with the type of substrate. Studies have shown that the cigarette linear burning rate varies between $1.3 \mathrm{~mm} / \mathrm{s}$ to $2.1 \mathrm{~mm} / \mathrm{s}$, depending on physical and chemical properties of the substrate. ${ }^{42}$ Salig $^{37}$ has shown that mock-up assemblies in which convective air flow at the crevice was blocked using aluminum foil recorded reduced temperatures by almost $300{ }^{\circ} \mathrm{C}$. It is evident from this study that the air flow barrier provided by the BF can temporarily slow or even completely stop the smoldering process in the cigarette and the CF. All of the tests wherein cigarette self-extinguishment was observed included BFs that were almost impermeable to air. 


\subsubsection{Highloft barriers}

The transient mass loss curves for mock-up assemblies provide insight into the smoldering behavior of FPUF/BF/CF combinations. The curves for mock-up assemblies with highloft BFs are plotted in Figure 2(a). All mock-ups tested with highloft BFs transitioned into self-sustained FPUF smoldering. The highloft barriers tested contained char-forming fibers, and their high porosity indicates greater surface areas favorable for surface oxidation reactions, which is conducive for enhanced smoldering. The heat flux provided by the smoldering $\mathrm{BF} / \mathrm{CF}$ combinations was more efficient at inducing self-sustained smoldering in the FPUF than the smoldering CF alone. Figure 2(a) shows that different highloft BFs are more or less efficient at inducing FPUF smoldering depending on their fiber content and bulk densities.

BF-1, BF-2 and BF-3 contain blends of polyester and flame-retarded rayon fibers. The smoldering index for BF-1 and BF-2 was identical (1.7) and the mass losses of complete assemblies incorporating these BFs at 45 min were approximately $7 \mathrm{~g} \pm 5 \mathrm{~g}$. The CVFs were $17 \% \pm 13 \%$. BF-3, which also contained a polyester and flame-retarded rayon blend, showed a slightly higher smoldering index (2.2) compared to BF1 and BF-2. The mass loss for the complete assembly was $10 \mathrm{~g} \pm 3 \mathrm{~g}$, and the CVF at the end of the $45 \mathrm{~min}$ test was $22 \% \pm 5 \%$. BF-3 has a lower bulk density $\left(0.031 \mathrm{~g} / \mathrm{cm}^{3}\right)$ as compared to BF-1 and BF-2. A lower bulk density with a similar fiber blend suggests that BF-3 had a higher thickness and greater porosity. Porosity is defined as the ratio of the total amount of void space in a material to the bulk volume occupied by the fibers. It is worth noting here that the permeability value for BF-3 was intermediate to those for BF1 and BF-2. However, the porous nature of BF-3 may permit easier oxygen transport to the reaction site by diffusion and convection. Previous studies ${ }^{43}$ have shown that the primary means of oxygen permeation through a fabric is diffusion, whereas air permeability measurements are based on air flow resistance. Since smoldering in systems such as those studied here is usually an oxygen-limited, surface-area-dependent process, the higher porosity provides an explanation for the more extensive smoldering of BF-3 (see Table 3 for char damage) and intense smoldering of the FPUF as compared to BF-1 and BF-2.

Among the highloft barrier materials, BF-4 and BF- 5 contained boric acid-treated cotton. BF- 5 was made of $100 \%$ boric-acid treated cotton, whereas BF-4 was a stratified blend of boric-acid treated cotton, FR rayon, and polyester. A layer of FR rayon/polyester blend was sandwiched between layers of boric acidtreated cotton battings. Mock-up with these BFs (BF-4 and BF-5) showed the high mass loss for the complete assemblies (13 g $\pm 6 \mathrm{~g}$ ), and CVFs were $33 \% \pm 14 \%$. BFs with boric acid-treated cotton exhibit enhanced smoldering compared to BFs with only FR rayon and polyester fiber blends. The boric acidtreatment of cotton fibers appears to be ineffective in reducing smoldering propensity in the presence of a smolder-prone cover fabric. In the presence of the smolder-prone $\mathrm{CF}$, the additional heat provided by char oxidation of the $\mathrm{CF}$ along with the heat from the smoldering cigarette was sufficient to induce piloted smoldering of boric acid-treated cotton. The char formation promoted in the presence of boric acid may have also encouraged smoldering via oxidation of this char. Studies have shown that the addition of inorganic additives (e.g., boric acid, phosphorus compounds) to cellulose can lead to a wide range of reactivities from enhancement to total inhibition of smoldering combustion ${ }^{44,48}$. Moreover, Ohlemiller ${ }^{44}$ has also shown that the effectiveness of boric acid as a smolder retardant is substantially reduced when used over a flammable substrate.

\subsubsection{Nonwoven barriers}


The mass loss curves for complete mock-up assemblies with nonwoven BFs covered with the smolderprone CF are shown in Figure 2 (b). All resulted in self-sustained smoldering of the FPUF by the end of the 45 min test. Among the nonwoven BFs, the mock-up with BF-9 exhibited a peculiar smoldering behavior. This mock-up did not start to lose mass until almost $22 \mathrm{~min}$ after the start of the test. However, the rate of mass loss for the mock-up assembly thereafter was very high. The smoldering was intense; so much so that the mock-up was manually extinguished before the end of the 45 min test. The CVF in this case was also higher (> $50 \%$ ) than found with the other nonwoven BFs evaluated in this study. The BF smolders along with the CF. BF-9 is a needle punched nonwoven material that has been treated to reduce flammability. The exceptionally high smoldering index of $<5.0$ for BF-9 is in line with previous studies wherein flame-retarded fabrics have shown higher smoldering propensities. ${ }^{45}$ The char of BF-9 was also very fragile and brittle. The digital images of charred BFs in Table 3 show that charred BF-9 lost its structural integrity as it decomposed during the smoldering process.

The best performing nonwoven BF was BF-10 in terms of minimum mass loss of the mock-up and CVF $(11 \% \pm 6 \%)$. BF-10 is a blend of flame retarded polyester and flame retarded rayon. The flame retardant systems incorporated in BF-10 may be more effective in lowering the smoldering propensity than those used in BF-8 and BF-9. The maximum char length on BF-10 was $100 \mathrm{~mm} \pm 2 \mathrm{~mm}$, which is similar to the maximum char length seen on the CF when tested with FPUF in the absence of a BF. However, the exact interaction between the smolder-prone $\mathrm{CF}$ and the $\mathrm{BF}$ is not clear at this stage and will be the subject of future studies. As noted from Table 3, BF-10 had a smaller charred area as compared to BF-9, and the smoldering index for BF-10 was 1.1. However, the char of BF-10 was so brittle that the charred portion of the BF completely disintegrated while separating components of the mock-up assembly after the test.

Mock-ups including nonwoven BFs (BF-21 and BF-22) consisting of highly flame-resistant para-aramid fibers also exhibited sustained smoldering behaviors. BF-21 is physically and thermally thin as compared to the other nonwoven BFs studied. As a result, heat transfer through this BF would be comparatively higher. ${ }^{14}$ The mock-up assembly with BF-21 showed mass loss in just 5 min after the start of the test, and the average CVF was $24 \% \pm 1 \%$. The smoldering index for BF-21 was 2.4, whereas BF-22 yielded a value of 1.3. BF-22 is a composite fabric with two layers of nonwoven para-aramid fibers and a woven meta-aramid fabric quilted together. This type of fabric is used as a thermal liner in fire-fighter's protective clothing and provides thermal insulation that protects the wearer from burn injury. The mass loss rate in mock-up assemblies with BF-22 was lower as compared to a BF with a similar thickness (BF-12). Better thermal insulation of BF-22 resulted in retaining a major proportion of heat within the layers of the BF and thereby restricting heat transfer to the FPUF. However, by the end of the $45 \mathrm{~min}$ test, the mock-up assembly with BF-22 covered with the smolder-prone CF had developed self-sustained smoldering.

BF-16 is a composite barrier with flame-retarded rayon and poly (lactic acid) fibers needlepunched on a woven glass-fiber fabric. BF-16 acts a passive fire barrier, and the flame-retarded rayon fibers char in place. The char forming ability of these fibers is favorable for the smoldering process. Thus, while the initial mass loss rate of the complete mock-up assembly was low, once the BF-16 started to smolder, the heat release from exothermic oxidation reactions of the $\mathrm{BF}$ char provided the required energy for smolder propagation through the barrier and into the FPUF. Beyond $30 \mathrm{~min}$ from the start of the test, significant smoldering of the FPUF $(\mathrm{CVF}=22 \% \pm 8 \%)$ was observed. The char of BF-16 (see Table 3$)$ had better structural integrity compared to the other nonwoven BFs (BF-8, BF-9, BF-10, and BF-21) due to the woven glass-fiber substrate. 


\subsubsection{Knitted barriers}

Knitted barrier fabrics (BF-11, BF-12 and BF-13) are produced by knitting core-spun yarn, which has an inherently fire-resistant fiber core (glass-fiber filament), and a sheath fiber that varies with performance requirements. BF-11 and BF-12 utilized flame-retarded acrylic fibers, whereas BF-13 had a flame-retarded rayon sheath. It can be noted from Table 2 that the knitted BFs have higher bulk densities and higher air permeabilities than highloft BFs. Since knitted fabrics have a loop structure, they have more open pores than woven fabrics; therefore, in general, the air permeability of knitted fabrics is higher than that of other fabrics of the same weight (compare BF-10 and BF-13). Thus, higher air permeabilities coupled with high bulk densities makes the structure more vulnerable to smoldering. The smoldering indices for BF-11, BF12, and BF-13 were 4.7, 3.5, and 1.7 respectively. The CVF increased with increasing area density of, BF$13\left(118 \mathrm{~g} / \mathrm{m}^{3}\right), \mathrm{BF}-12\left(148 \mathrm{~g} / \mathrm{m}^{3}\right)$, and BF-11 $\left(207 \mathrm{~g} / \mathrm{m}^{3}\right)$. The smoldering indices for BF-11 and BF-12 are consistent with the longer char lengths recorded (see Table 3). The lower smoldering propensity for the mock-ups with BF-13 may be associated with its lower bulk density and the type of sheath fibers. Mass loss curves for complete assemblies incorporating knitted barriers with smolder-prone cover fabrics are shown in Figure 2(d). BF-11 showed the highest mass loss rate followed by BF-12 and BF-13.

BF-23 is a knitted fabric with a cotton/glass fiber blend. The base fabric has an area density of $153 \mathrm{~g} / \mathrm{m}^{2}$ and is backcoated with an intumescent flame-retardant system containing phosphorus and acrylic (85 wt \% add-on). The coated fabric has an area density of $284 \mathrm{~g} / \mathrm{m}^{2}$ and is completely impermeable to air. With BF-23 interposed between FPUF and the smolder prone $\mathrm{CF}$, the cigarette extinguished within 3 min from the start of the test, and no smoldering on the $\mathrm{CF}$ was observed. As mentioned earlier, the initial interaction between the smoldering cigarette and the substrate leads to reduced cigarette burn rate. ${ }^{46}$ The degree of reduction depends on the characteristics of the underlying materials (thermal conductivity, heat capacity, gas permeability, etc.). The reduction in cigarette burn rate may be minimal or the cigarette may extinguish. We propose that the impermeability of backcoated BF-23 to air and other gases is largely responsible for extinguishing the cigarette and lowering smoldering propensity. The mock-up with BF-23 showed no change in mass throughout the test duration, and the FPUF was completely protected in the presence of BF23.

\subsubsection{Woven barriers}

Four out of five of the woven barrier fabrics examined in this study were comprised of woven glass filaments. BF-20 is a para-aramid/melamine fiber-blend fabric generally used as an outer shell in fire fighter turnout gear. Such a fabric provides flame protection and serves as a primary defense to mechanical injury, heat, and fire. The inherently fire-resistant fibers in BF-20 have high decomposition temperatures (in excess of $350{ }^{\circ} \mathrm{C}$ ), and it therefore takes longer times to initiate smoldering by a smoldering cigarette. Only a very small amount of localized smoldering was seen in the vicinity of the smoldering ignition source. The CF also did not smolder significantly. This observation can be attributed to an interaction between the smoldering propensities of the $\mathrm{CF}$ and the $\mathrm{BF}$. As mentioned earlier, smoldering in the $\mathrm{CF}$ produces enough heat to char the adjacent pristine fabric to the point where smoldering can start. The heat generated is either dissipated into the underlying BF or conducted laterally along the CF. In the case of the FPUF/BF-20/CF combination, a large amount of heat was apparently dissipated to the $\mathrm{BF}$, thereby reducing lateral heat transfer in the $\mathrm{CF}$ and limiting further smolder propagation. The CVF was negligible $(0.6 \% \pm 0.1 \%)$, and the mock-up assembly self-extinguished before the end of the 45 min test. BF-17, BF-18, and BF-19 consist 
of woven glass filaments. These BFs are completely impermeable to gases. With very small thicknesses $(<0.3 \mathrm{~mm})$, these barrier fabrics have bulk densities in excess of $0.750 \mathrm{~g} / \mathrm{cm}^{3}$. Mock-up assemblies consisting of such BFs self-extinguish as soon as the cigarette is completely burned or self-extinguished. The slight mass losses recorded for the complete mock-up assemblies $(<1 \mathrm{wt} \%)$ were either within the experimental error or due to gaseous mass loss as a consequence of CF smoldering.

In contrast, mock-ups incorporating BF-15, which is a woven fabric made from core-spun yarn, exhibited a high smoldering propensity (smoldering index of 5.0). BF-15 is a physically and thermally thin barrier, and the open weave results in high air permeability. Once sustained smoldering was established in the CF, around 25 min, the mass loss rate of the mock-up assembly increased rapidly (see Table 5). The FPUF smoldered significantly resulting in CVFs of $50 \% \pm 22 \%$ at the end of 45 min test.

Typical digital images of the char formed on various BFs during the smoldering ignition tests on mock-ups consisting of FPUF/BF/CF components are shown in Table 3. The qualitative analysis of chars on BFs suggests that typically highloft and nonwoven structures have very low residual strength, whereas the knitted and woven structures had better structural integrity compared to highloft and non-woven fabrics. Quantitative analysis of BF char is discussed below.

\subsection{Char length on BF and CVF of FPUF}

Values of CVF for the FPUF are plotted against averages of maximum char length on the BFs in Figure 5. The CVFs show an almost linear relationship $\left(\mathrm{R}^{2}=0.90\right)$ with non-zero char length values. It is also clear from the data in Figure 5 that highly significant differences in char lengths are produced due to variability in barrier fabric types. BF-9 produced the longest char length of $220 \mathrm{~mm} \pm 44 \mathrm{~mm}$ followed by BF-15 $(191 \mathrm{~mm} \pm 20 \mathrm{~mm})$ and BF-11 (175 mm $\pm 14 \mathrm{~mm})$. BF-15 and BF-11 have high air permeability levels with open woven and knitted structures respectively. However, both of the BFs are comprised of similar core-spun yarn. The high air permeability and thermal thinness of the two BFs facilitate increased oxygen supply to the smolder reaction zone, thereby supporting increased BF smolder rates, which result in greater heat release and peak temperature in the reaction zone. ${ }^{41}$ The increased BF smoldering accelerates the rate of smolder spread both laterally over the fabric surface and into the FPUF. The longer char lengths on BF9 are likely attributable to the use of a flame retardant treatment that reduces smoldering resistance. ${ }^{47}$ 


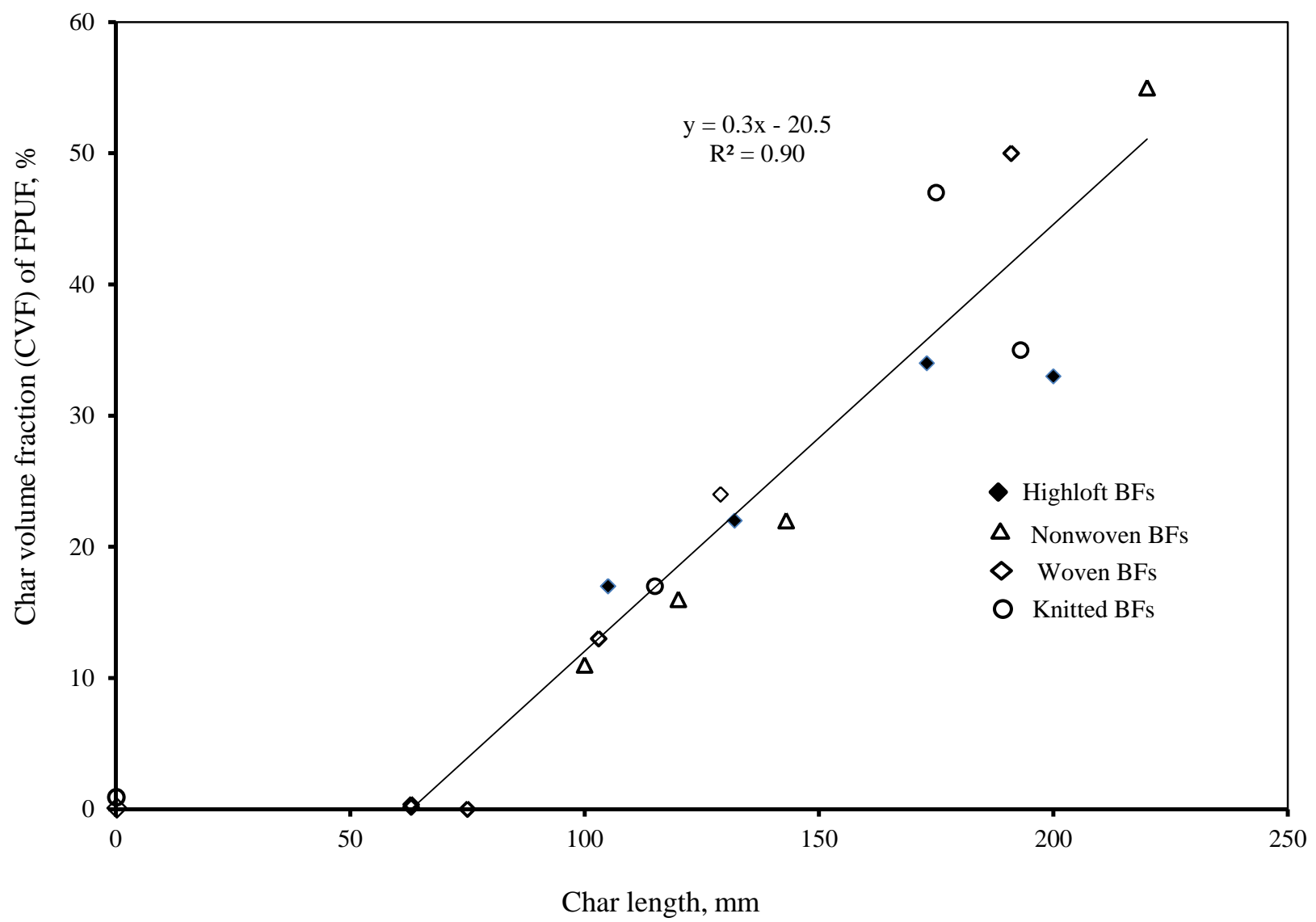

Figure 5. CVF of FPUF versus char length on BF

The shortest char lengths $(<75 \mathrm{~mm})$ were produced on BFs having the lowest air permeability and which did not lead to sustained smoldering in the FPUF. Such lengths are comparable to the cigarette smolder length. The results of the char length analysis suggest that for a given BF structure, air permeability level has a significant effect on char lengths and smoldering propensity BF and thereby the FPUF.

\subsection{Air permeability of BF and CVF of FPUF}

Figure 6 shows a plot of CVF of FPUF after the 45 min smoldering ignition test versus the air permeability for the BFs. The BF smoldering propensity and the CVF of FPUF are almost $\left(\mathrm{R}^{2}=0.5\right)$ linearly related with air permeability, which suggests that additional parameters such as chemistry of fiber, fabric structure, and/or bulk density are responsible for the observed variations. Thus, air permeability is not a sufficient condition for smolder propagation in BFs, at least for configurations considered in this study. A low permeable BF structure restricts oxygen transport to the FPUF, thereby suppressing smolder propagation in the FPUF. The FPUF is mostly protected from smoldering with very little discoloration due to thermal impact. Studies ${ }^{20,42,48}$ that have varied air permeability levels of selected upholstery fabrics while keeping the fiber composition the same have reported differences in smoldering times, char lengths and char areas. Donaldson et $\mathrm{al}^{42}$ found that decreasing air permeability by a factor of 8 reduced the smoldering rate by $14 \%$. 


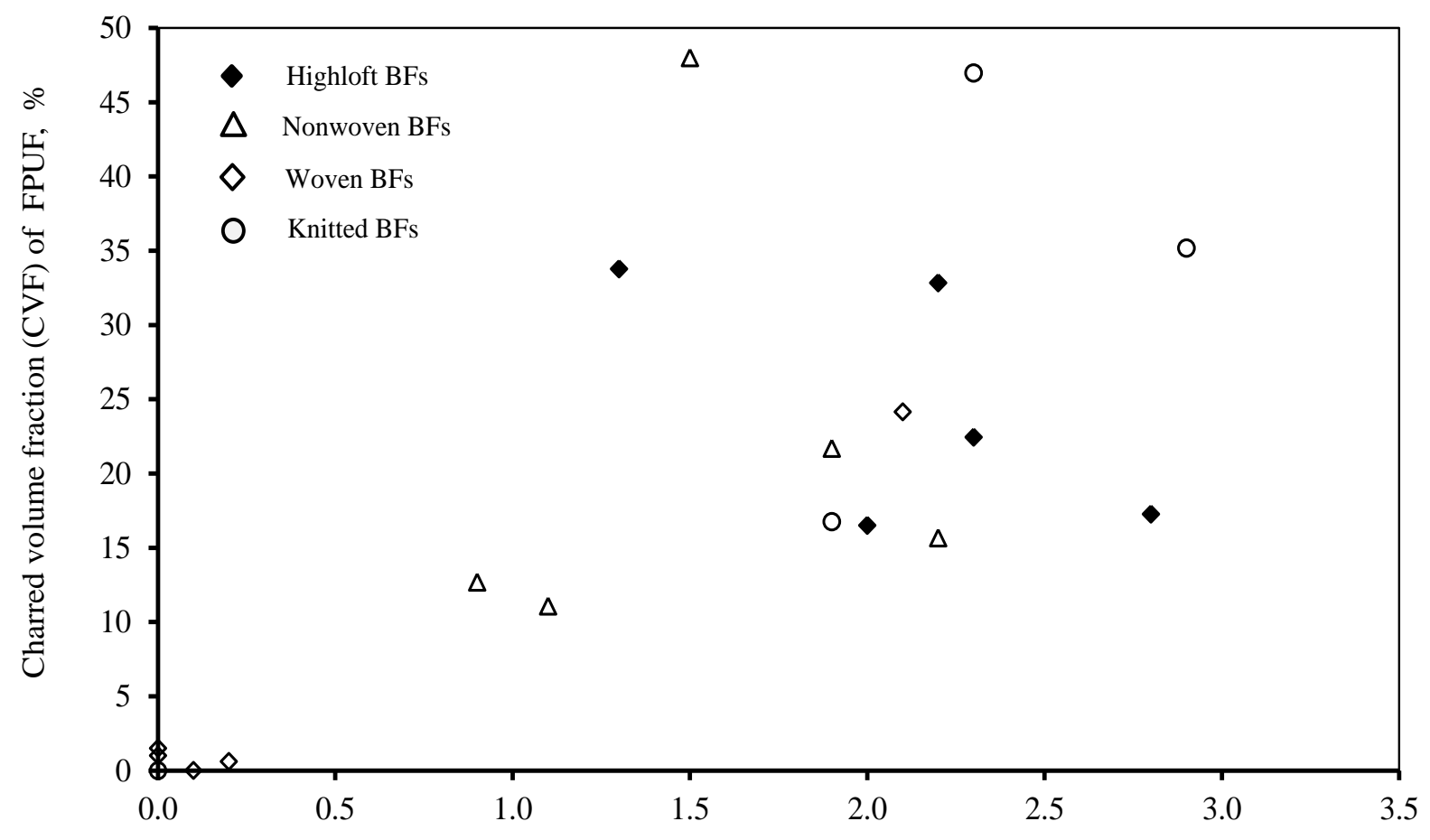

Air permeability, $\mathrm{m} / \mathrm{s}$

Figure 6. CVF of FPUF at the end of 45 min smoldering ignition tests versus air permeability.

\section{Conclusions and Future Work}

The smoldering propensity of BFs were assessed in terms of char length produced on BFs, mass loss of the standard mock-up assembly, and the CVF of the FPUF substrate when tested in a mock-up configuration using a cigarette ignition source. A smoldering index for BFs has been derived from CVF by varying the BF component in the FPUF/BF/CF mock-up systems, while holding the other two components constant. Smoldering could only be initiated in the FPUF when the BF was covered with a smolder-prone CF. Results of this study suggest that the smolder-prone CFs when placed over a number of BFs are capable of releasing sufficient heat to initiate the char-oxidation smoldering process in the BF, which can subsequently transmit the heat to the underlying FPUF. The smoldering propensity of BFs and thereby the amount of heat transmitted to the FPUF varies depending on the BF structure, fiber content, air permeability, and bulk density. The lower the smoldering propensity of the BF, the less likely is the development of self-sustained smoldering in the FPUF.

Of the $20 \mathrm{BFs}$ tested in this study, mock-ups with five BFs self-extinguished and passed (see Table 5) the smoldering ignition test criterion described in CPSC's proposed regulation for RUF (16 CFR 1634). The BFs that exhibited self-extinguishing behaviors contained inherently fire resistant fibers and had air permeability values of less than $0.2 \mathrm{~m} / \mathrm{s}$. BF-9, BF-11 and BF-15 had the highest smoldering propensities, resulting in charring of a large fraction of the FPUF.

BFs with highloft structures, which have higher porosity, favor surface oxidation reactions and hence extensive smoldering. Compared to their performance in residential mattresses, the boric acid treated cotton battings were less effective in reducing the smoldering propensity of the mock-up configuration in this 
study, i.e., containing smolder-prone FPUF and CF. Other flame retardant treatments and use of char forming fibers showed a greater tendency for BF smolder in the presence of the smolder-prone CF. For BFs with similar fiber composition and similar structures, the smoldering propensity increased with an increase in bulk density. A less permeable BF structure restricts oxygen transport to the FPUF, thereby suppressing smolder propagation in the FPUF. However, air permeability is not a sufficient condition for smolder propagation.

It is clear from the above discussion that smoldering ignition of FPUF by BFs is influenced by incident heat flux, oxygen availability, and BF properties. BF properties such as structure, density, type of weave, surface treatment, compressibility, air permeability, and fiber chemistry (charring, low charring and non-charring fibers) influence thermal properties such as thermal diffusivity, thermal resistance, and thermal conductivity. Both thermal diffusivity and thermal resistance are derived parameters and are functions of thermal conductivity. Thermal diffusivity is defined as the ratio between thermal conductivity and the volumetric heat capacity. Thermal resistance is the ratio of thickness and thermal conductivity of a fabric. Thermal conductivity is an intrinsic property of a material that indicates its ability to conduct heat (energy per unit area per unit time) divided by the temperature gradient. For textile materials, air within the fabric structure is the most important factor controlling the conductivity and is strongly influenced by the fabric structure. The fabric thickness, density, and heat capacity all play a role in determining the thermal conductivity and hence thermal resistance and thermal diffusivity of barrier fabrics. It is expected that the study of aforementioned thermo-physical properties will be useful in further understanding mechanisms of smoldering in barrier fabrics. Future work is planned to determine explicit relations between BF's ability to convey heat from a $\mathrm{CF} /$ covered cigarette to the FPUF, such as to induce smoldering in the FPUF. 


\section{References}

[1] 16 CFR Part 1633 Standard for the flammability (open- flame) of mattress sets. Consumer Product Safety Commission. March (2007). Available from:

http://www.cpsc.gov/businfo/frnotices/fr06/mattsets.pdf.

[2] Technical Bulletin 129: Flammability Test Procedure for Mattresses for Use in Public Buildings, October 1992, State of California Department of Consumer Affairs Bureau of Home Furnishings and Thermal Insulation 3485 Orange Grove Avenue North Highlands, CA 95660-5595.

[3] Technical Bulletin 603: Requirements and Test Procedure for Resistance of a Mattress/Box Spring Set to a Large Open-Flame, July 2003, State of California Department of Consumer Affairs Bureau of Home Furnishings and Thermal Insulation 3485 Orange Grove Avenue North Highlands, CA 95660-5595, available from http://www.peopleforcleanbeds.org/cal\%20burn\%20test\%20603.pdf.

[4] Technical Bulletin 133, Flammability Test Procedure for Seating Furniture for Use in Public Occupancies, State of California, Department of Consumer Affairs, Bureau of Home Furnishings and Thermal Insulation, January (1991).

[5] Flammability Requirements for Aircraft Seat Cushions, Appendix F, Part II of Section 25.853 of the Federal Aviation Regulations (FAR), Federal Aviation Administration, see also Flammability Requirements for Aircraft Seat Cushions, Advisory Circular Number 25.853-1, Federal Aviation Administration, September 17, 1986.

[6] Nazaré S, Davis R. A review of fire-blocking technologies for soft furnishings, NIST Technical Note 1728, November 2011, National Institute of Standards and Technology, Gaithersburg MD.

[7] Zota AR, Rudel RA, Morello-Frosch RA, Brody JG. Elevated house dust and serum concentrations of PBDEs in California: Unintended consequences of furniture flammability standards? Environmental Science and Technology. 2008; 42, (21):8158-8164.

[8] Chivas C, Guillaume E, Sainrat A, and Barbosa V. Assessment of risks and benefits in the use of flame retardants in upholstered furniture in continental Europe, Fire Safety Journal. 2009; 44(5): 801-807.

[9] Technical Bulletin 117-2013: Requirements, Test Procedure and Apparatus for Testing the Smolder Resistance of Materials Used in Upholstered Furniture, Department of Consumer Affairs, Bureau of Home Furnishings and Thermal Insulation, June (2013).

[10] Standard No. 302: Flammability of Interior Materials, Federal Motor Vehicle Safety Standards, U.S. Department of Transportation, September 24, 1998.

[11] Krasny JF, Parker WJ, Babrauskas V. Fire behavior of upholstered furniture and mattresses., William Andrew Publishing, LLC Norwich, New York, USA. 2001 Edition.

[12] Damant GH. Cigarette ignition of upholstered furniture. Journal of Fire Sciences. 1995; 13:337 349.

[13] Mikelson DA, Evaluation of staple polyester/microfiberous polyolefin blended batting as a potential thermal insulating material for clothing. Technical Report NATICK/TR-81/007, United States Army Natick Research and Development Laboratories Natick, Massachusetts 01760. June 1980.

[14] Nazaré S, Pitts W, Flynn S, Shields J and Davis R, Towards a New Approach for Evaluating FireBlocking Barrier Fabrics, NIST TN 1798, April 2013, National Institute of Standards and Technology, Gaithersburg MD. DOI http://dx.doi.org/10.6028/NIST.TN.1798.

[15] Spears AW, Rhyne AL, and Norman V. Factors for consideration in a test for cigarette Ignition Propensity on soft furnishings, Journal of Fire Sciences 1994; 1: 59-84. 
[16] Upholstery Furniture Action Council, UFAC Central Box 2436 High Point, NC 27261 http://www.ufac.org/method1.htm

[17] Technical Bulletin 116: Requirements, Test Procedure and Apparatus for Testing the Flame Retardance of Upholstered Furniture, State of California Department of Consumer Affairs Bureau of Home Furnishings and Thermal Insulation 3485 Orange Grove Avenue North Highlands, CA 95660-5595, available from http://www.bhfti.ca.gov/industry/116.pdf.

[18] ASTM E 1352-08a, Standard Test Method for Cigarette Ignition Resistance of Mock-Up Upholstered Furniture Assemblies, ASTM International, 100 Barr Harbor Drive, PO Box C700, West Conshohocken, PA 19428-2959.

[19] NFPA 261: Standard method of test for determining resistance of mock-up upholstered furniture material assemblies to ignition by smoldering Cigarettes, 2013 Edition , National Fire Protection Association, Quincy.

[20] Travers EB, and Olsen NF. Effect of air permeability on smoldering characteristics of cotton upholstery fabrics. Textile Research Journal. 1982; 52:598-604.

[21] Upholstery Furniture Action Council, UFAC Central Box 2436 High Point, NC 27261 http://www.ufac.org/method3.htm

[22] ASTM E1353-08a, standard test method for cigarette ignition resistance of components of upholstered furniture. ASTM Standards for Upholstered Furniture, Mattresses and Bedding, ASTM International, 100 Barr Harbor Drive, PO Box C700, West Conshohocken, PA 194282959.

[23] NFPA 260 Standard methods of tests and classification system for cigarette ignition resistance of components of upholstered furniture, National Fire Protection Association (NFPA), 1 Batterymarch Park, Quincy, MA 02269-9101 USA.

[24] Williams SS, Damant G., Rate of weight loss as an aid to evaluate the smoldering propensity of upholstery fabrics. Journal of Consumer Product Flammability, 8, June; 89-104, 1981

[25] 16 CFR Part 1634, Standard for the flammability of residential upholstered furniture (proposed rule). Consumer Product Safety Commission. March (2008). Available from: http://www.cpsc.gov/businfo/frnotices/fr08/furnflamm.pdf.

[26] Madacsi JP, and Neumeyer JP. A comparison of smolder resistance standards for boric acid treated cotton batting, Journal of Consumer Product Flammability. 1982; 9:3-10.

[27] ASTM D5238 - 10 Standard test method for smoldering combustion potential of cotton-based batting. ASTM Standards for Upholstered Furniture, Mattresses and Bedding, ASTM International, 100 Barr Harbor Drive, PO Box C700, West Conshohocken, PA 19428-2959.

[28] Wakelyn PJ, Wolf S, Oliver K. Cotton batting fire-blocking barriers for soft furnishings. Presented at the 14th Annual Business Communications Company, Inc. (BCC) Conference on Flame Retardancy June 3, 2003. Stamford, CT.

[29] Zammarano M, Matko S, Pitts WM, Fox D M, Davis RD. Towards a Reference Polyurethane Foam and Bench Scale Test for Assessing Smoldering in Upholstered Furniture, Polymer Degradation Stability, In press, available at http://www.sciencedirect.com/science/article/pii/S0141391013004151

[30] http://www.frazierinstrument.com/products/fap/fap-faq.html\#Air\%20Permeability\%20$\% 20$ Size\%20of\%20Unit:

[31] Olsen, NF and Bollinger JR. Filtered and non-filtered cigarette ignition of cotton upholstery fabrics. Textile Research Journal. 1980; 50: 310-315.

[32] Zammarano M, Krämer R H, Szabolcs M, and Davis RD. Standard Operating Procedures for Smolder Ignition Testing of Upholstery Fabrics, TN1775, November 2012. 24 pgs. National 
Institute of Standards and Technology, Gaithersburg MD. Available at http://www.nist.gov/manuscript-publication-search.cfm?pub_id=912584

[33] Zammarano M, Krämer RH, Matko S, Mehta S, Gilman JW, Davis RD. NIST TN 1747 - Factors Influencing the Smoldering Performance of Polyurethane Foam. 2012.

[34] Ihrig AM, Spears AW, Rhyne AL, and Norman V. Factors involved in the ignition of cellulosic upholstery fabrics by cigarettes, Journal of Fire Sciences. 1986; 4: 237-260.

[35] http://www.nist.gov/customcf/get_pdf.cfm?pub_id=902075

[36] Damant GH, Flammability aspects of upholstered furniture. Journal of Consumer Product Flammability. 1976; 3; 21-61.

[37] Salig RJ. The Smoldering Behavior of Upholstered Polyurethane Cushionings and Its Relevance to Home Furnishing Fires. Thesis (M.S.). Cambridge, MA: Massachusetts Institute of Technology; 1982.

[38] Ortiz-Molina MG, Mak AY, Tesoro GC, Toong TY. Report, Smoldering Combustion of Cellular Plastics and Its Transition to Flaming or Extinguishment. Final Report. Department of

Mechanical Engineering, Massachusetts Institute of Technology for Products Research Committee (RP-76-U-3) June 1979.

[39] Rogers FE, Ohlemiller TJ, Kurtuz A, and Summerfield M. Studies of the smoldering combustion of flexible polyurethane materials. Journal of Fire and Flammability, 1978; 9:5-13.

[40] Chao CYH., and Wang JH., Comparison of the thermal decomposition behavior of a non-flame retarded and a fire retarded flexible polyurethane foam with phosphorus and brominated additives. Journal of Fire Sciences. 2001; 19:137-156.

[41] Ohlemiller TJ, Smoldering combustion. In chapter 11, Section 2, 171-179, SFPE Handbook of Fire Protection Engineering, 2nd Edition. Eds DiNenno PM et al.

[42] Donaldson DJ, Yeadon DA, and Harper RJ Jr. Smoldering characteristics of cotton upholstery fabrics, Textile Research Journal. 1981; 51:196-202.

[43] Ohlemiller TJ, Villa KM, Braun E, Eberhardt KR, Harris RH Jr., Lawson JR, and Gann RG. Test methods for quantifying the propensity of cigarettes to ignite soft furnishings, NIST SP 851, August 1993, National Institute of Standards and Technology, Gaithersburg MD.

[44] Shafizadeh F, Bradbury AGW, DeGroot WF, and Aanerud TW. Role of inorganic additives in the smoldering combustion of cotton cellulose, Ind. Eng. Chem. Prod. Res. Dev. 1982; 21, (1).

[45] Tesoro GC, The fire safety of upholstered furniture: An evaluation of the state-of-the art and potential improvements, Journal of Consumer Product Flammability. 1981; 8:132-143.

[46] Lewis LS, Morton MJ, Norman V, Ihrig AM, and Rhyne AL. The effects of upholstery fabric properties on fabric ignitabilities by smoldering cigarettes II. Journal of Fire Sciences, 1995; 445471.

[47] Damant GH, and Young MA., Flammability classification of fabrics used as upholstery furniture coverings, Journal of Consumer Products Flammability, 4:60-113, 1977.

[48] Fresman G., A study in smoldering test behavior versus air flow variations in fabric, Journal of Coated Fabrics. 1984; 13 (3): 184-192.

[49] Taylor BN and Kuyatt CE, Guidelines for Evaluating and Expressing the Uncertainty of NIST Measurement Results, NIST Technical Note 1297, 1994 Edition (Supersedes 1993 Edition), Gaithersburg, MD, 20878.

[50] Evaluation of measurement data - Guide to the expression of uncertainty in measurement. JCGM 100:2008. http://www.bipm.org/utils/common/documents/jcgm/JCGM_100_2008_E.pdf 